\title{
Identification of changes in mechanical properties of sandstone subjected to high temperature: meso-and micro-scale testing and analysis
}

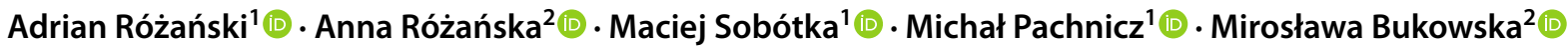

Received: 11 November 2020 / Revised: 9 January 2021 / Accepted: 26 January 2021 / Published online: 13 February 2021

(c) The Author(s) 2021

\begin{abstract}
Material properties largely depend on their structure, and are strongly dependent on the scale of observation. Under the influence of various processes, the structure of a material can undergo evolution, which leads to major changes in the mechanical parameters and morphology of the medium. To understand the behaviour of a given material exposed to the influence of various factors, e.g. loading and temperature treatment, and to be able to modify it appropriately, it is crucial to recognize its structure both in the scale of engineering applications and at the micro-scale. The article proposes a procedure for assessing changes in the structure of sandstone exposed to the temperature treatment. The presented procedure allows the morphology of the material to be evaluated and the influence of temperature treatment on mechanical parameters of rocks to be analysed, by combining use of different laboratory techniques. The changes in rock material have been characterized using three investigative techniques, i.e. a uniaxial compression test, nanoindentation and micro-computed tomography. The uniaxial compression tests were carried out for 11 different temperature values in the range of $23-1000{ }^{\circ} \mathrm{C}$, which enabled the determination of the change in uniaxial compressive strength and Young's modulus of the sandstone as a function of temperature. Micro-scale laboratory tests were utilised to identify changes in the mechanical and morphological parameters of the sandstone exposed to the temperature of $1000{ }^{\circ} \mathrm{C}$. The results were referred to those obtained for the reference samples, i.e. not subjected to heating $\left(T=23{ }^{\circ} \mathrm{C}\right)$. Comparison of the results showed an evident relation between the microstructure changes and the mesoscopic properties.
\end{abstract}

Keywords Rock material $\cdot$ Uniaxial compressive strength $\cdot$ Nanoindentation $\cdot$ X-ray tomography $\cdot$ Microstructure

\section{Introduction}

Due to the phenomenon of the thermal expansion of minerals and the initiation of many chemical and mineral transformations, the temperature of the rock medium can be a factor that significantly modifies the original properties of rocks, e.g. crack density [1], mineral composition and texture [2], mechanical parameters [3] and intrinsic permeability [4]. This is a significant research problem in various engineering

Adrian Różański

adrian.rozanski@pwr.edu.pl

1 Faculty of Civil Engineering, Wroclaw University of Science and Technology, Wybrzeże Wyspiańskiego 27, 50-370 Wrocław, Poland

2 Department of Mechanical Devices Testing and Rocks, Laboratory of Mining Geomechanics, Central Mining Institute, Katowice, Poland applications [5] such as underground coal gasification, deep exploitation [6], oil and gas exploitation, underground nuclear waste storage [7], extraction of geothermal energy [8]. Furthermore, thermally induced changes in rocks' properties can be utilized in geoengineering practice to modify geomaterials. For instance, some mining wastes could be used in civil engineering, provided that their mechanical parameters would meet the relevant design requirements. Sometimes, to meet these requirements, it is necessary to improve the waste material. Then, thermal modification can be an effective method to achieve this goal. The current development of mining waste management technologies requires to be more extensively explored from both the practical and scientific points of view. Therefore, the need to conduct research works aimed at developing new technologies of processing and utilization of hard coal mining waste is justified. The article reports the preliminary part of a research project, which aims to assess and contribute to 
a better understanding of temperature-induced changes in physical and mechanical properties of rocks. Thus, the main goal of presented study is to formulate a new methodology of combined micro- and meso-scale laboratory investigation of changes in rock mechanical parameters due to temperature treatment. This methodology is going to be used in the future to "control" a process of thermal modification of rock material.

During recent decades many papers describing the influence of temperature treatment on a number of properties of various types of rocks were published. Their results unequivocally indicate a clear dependence between the physical, mechanical and thermal properties of rocks and the temperature acting on them, its value and the duration of heating. In [9] granitic rocks were tested against the influence of temperature treatment on physical and mechanical properties such as open porosity, gas permeability, P-wave velocity, strength, and Young's modulus. In particular, the mechanical parameters were found to be dependent on the microcracks' density. The changes in strength and mineral composition of the Hawkesbury sandstone at various temperatures (ranging from 25 to $950{ }^{\circ} \mathrm{C}$ ) were reported in [10]. Analogical experiments and similar conclusions were drawn by Sygała et al. [11], however the analyses concerned a different rock and the temperature ranging from 400 to $600{ }^{\circ} \mathrm{C}$. The review [12] indicated the effect of changes in normalized elastic modulus as well as tensile strength of sandstone during and after high-temperature treatment.

The changes in the properties result from the thermal stresses developing under the influence of high temperature which, depending on the thermal expansion of constituent minerals and intergranular contacts, cause microcracks that gradually expand with the increasing temperature [13]. Such effect is of particular importance in brittle rocks [14]. In addition, accompanying phenomena such as dehydration or decarbonisation of rocks contribute to the changes mentioned above. Chemical transformations activated under the influence of temperature may result in polymorphic transformation, melting and even disappearance of some minerals [15]. Chen et al. [16] observed also that the connection between the minerals within the granite becomes weaker with increasing heat treatment temperature.

In natural conditions, rock strength is affected by such factors as: mineral composition, structure and texture characteristics, the strength of individual mineral grains and the nature of contacts between them. In the case of high-temperature action, an additional factor influencing the strength parameters of rocks is the thermal expansion of rock forming minerals. These may have different thermal expansion properties, for example, thermal expansion coefficient of quartz and mica is about 4 times greater than the one of feldspar [17]. Depending on the coefficient of thermal expansion of individual minerals, changes along the crystallographic axes occur under the influence of temperature. This leads to an increase in contact areas at the boundaries of mineral grains and damage to the rock skeleton during heating [18]. According to Pinińska [19], the kinematics of strength transformations and the subsequent change in the value of mechanical parameters depend on the strengthening or weakening of contacts between grains. The thermal expansion of rocks also affects their physical properties. It is necessary to take into account the change in the shape, volume, mass, bulk density and velocity of elastic waves in the rock medium.

Keshavarz et al. [20] investigated the damage and changes in mechanical properties of thermally loaded gabbro. The samples were heated to seven prescribed nominal temperatures, i.e., $150,300,500,600,700,800$ and $1000{ }^{\circ} \mathrm{C}$. The analyses were based on the results of uniaxial compression tests, elastic wave velocity, acoustic emission as well as the microscopic examination. Based on the observations carried out, three zones of damage were distinguished in which one can find an analogy to the observations contained in the work of Dimitriyev et al. [21]. In the first zone, from ambient temperature to $600{ }^{\circ} \mathrm{C}$, the growth of micro-cracks occurred at a slow and steady rate and was caused by thermal expansion. In the second zone, within the temperature range of 600 to $700{ }^{\circ} \mathrm{C}$, a significant decrease in uniaxial compressive strength and velocity of elastic waves, caused by various phase transitions and cracks of fluidal inclusions, was observed. In the third zone, above $700{ }^{\circ} \mathrm{C}$, degradation of all the measured parameters continued at a constant rate; at the temperature of $1000^{\circ} \mathrm{C}$ a considerable decrease in compressive strength and stiffness was identified. It was also found that the temperature of $600{ }^{\circ} \mathrm{C}$ is the critical temperature at which significant changes in the physical and mechanical properties of the tested rock samples occur. Above this temperature, a substantial reduction in both, the strength and modulus of elasticity, was found.

It is obvious that changes in all the parameters which describe the macroscopic properties of rocks, and particularly changes in the mechanical properties, are a consequence of microstructural changes occurring in the rock matrix. Under the influence of high temperature, the values of basic geomechanical parameters (such as uniaxial compressive strength (UCS), Young's modulus and Poisson's ratio) change $[22,23]$. To accurately recognize the microscopic mechanism of the macroscopic changes in mechanical parameters, it is necessary to characterize the microstructure of rocks after the influence of high temperature. The work [24] indicates that due to the lack of effective microscopic observation techniques, the mechanisms of the deformation of rocks under the influence of temperature were not properly taken into account in earlier studies. As far as we know, to date only few studies of microstructure evolution in rocks due to high temperature have been carried out $[24,25]$. Such 
evolution concerns skeleton and pore space changes within the internal microstructure of rock and the development of microcracks. Usually the methods such as micro-computed tomography [26] or nanoindentation tests [27], which provide accurate identification of material microstructure, are used separately. Furthermore, up to now, far too little attention has been paid to establish cross-scale relations of thermally induced changes in rocks' properties.

Since the mechanical properties, at the scale of engineering applications, are strongly affected by microstructural changes we aim at developing a cross-scale methodology combining micro- and meso-scale laboratory tests. The main goal of the present study (being a preliminary phase of our long-term research programme) is the identification of the influence of temperature treatment on the mechanical parameters of rocks. For this purpose we propose the simultaneous use of three, methodologically different, laboratory techniques, i.e., unconfined compression tests (meso-scale observation) as well as nanoindentation and X-Ray microcomputed tomography (micro-scale tests). Hence, we use commonly known techniques but the importance and originality of this study are that it combines them in one common approach. In particular, morphological and mechanical properties of microstructure are investigated at the micro-scale. The obtained result are then related to meso-scale results of uniaxial compressive strength (UCS) and Young's modulus (E). Two types of rock are considered, namely, very fine- and medium-grained sandstone. It is shown that the combined use of different investigation techniques is a useful tool in the perspective of further studies concerning the effects of temperature treatment on the properties of rocks.

\section{Materials, methods and research programme}

The meso- and microstructure research was carried out on sandstones taken from two research polygons constituting the areas of active mines located in the Upper Silesian Coal Basin (USCB) in Poland. The sandstones were characterized by various grain sizes and different stratigraphic age. One of the samples was a very fine-grained sandstone from the Rudzkie Beds, whereas the other one was a medium-grained sandstone taken from the younger stratigraphic Łaziskie Beds (Fig. 1). Both of the rocks were characterized by an average uniaxial compressive strength determined in an airdry state according to the classification adopted for the carboniferous rocks in the USCB [28].

The proposed research programme consists of tests at meso-scale (uniaxial compression tests) and micro-scale (X-Ray micro-computed tomography and nanoindentation tests). Prior to the tests, the samples (cylindrical specimens with the diameter of $30 \mathrm{~mm}$ and height of $60 \mathrm{~mm}$ ) were divided into two groups. The first group was further tested in a air-dry state and the second group was subjected to thermal treatment at temperature ranging from 100 to $1000{ }^{\circ} \mathrm{C}$ (each $100{ }^{\circ} \mathrm{C}$ ). A resistance furnace was used to heat the rock specimens in the period of $8 \mathrm{~h}$. The rate of temperature increase was set to $16^{\circ} \mathrm{C} / \mathrm{min}$. After the heating process, the samples were placed in a desiccator until they returned to the ambient temperature. This means, and it should be clearly emphasized, that the samples were tested after thermal treatment. Therefore, what was focussed on are the effects of one-time thermal treatment on deformation and mechanical parameters of rocks (after-heating changes are investigated). An example of a series of the sandstone samples after exposure to different nominal temperatures is shown in Fig. 2.

As can be seen in Fig. 2, the effect of temperature treatment up to $1000{ }^{\circ} \mathrm{C}$ is revealed by the change of colour. Grey, light grey or beige sandstones changed their colour to pink, light beige or brown. In some cases, intensification of colour change occurred locally. The colour change of sandstones is associated with mineral transformations, mainly due to oxidation of iron-containing minerals to hematite. Lighter colour is associated with transformations of chlorite [2].

The meso-scale tests were carried out for all nominal temperature values (Fig. 2). This means the UCS and Young's modulus were evaluated for different temperature treatment "regimes" at every $100{ }^{\circ} \mathrm{C}$. For the development of the methodology for identifying microstructural changes due to temperature, the tests at the micro-scale were limited to two extreme values of temperature, i.e. a reference case of ambient temperature $T=23{ }^{\circ} \mathrm{C}$ and the highest of considered temperatures, $T=1000{ }^{\circ} \mathrm{C}$. This quite obvious choice of extreme temperature values results from the expectation the differences in the microstructure to be most evident. In the further part of this Section all laboratory techniques used in the work are discussed in detail.

\subsection{Meso-scale experiments}

The meso-scale studies were conducted in the Laboratory of Mining Geomechanics of the Central Mining Institute, Poland. Cylindrical specimens with a diameter of $30 \mathrm{~mm}$ and a length of $60 \mathrm{~mm}$ (slenderness 2) were prepared from the collected cores, in accordance with the recommendations of the International Society for Rock Mechanics and Rock Engineering (ISRM). The tests were carried out using the servo-controlled testing machine MTS-810 with maximum load ranging up to $1000 \mathrm{kN}$ (Fig. 3). The uniaxial compression tests were performed within the full range of deformation of the samples at the displacement rate of $0.01 \mathrm{~mm} / \mathrm{s}$. The procedure was executed in accordance with recommendations of the ISRM [29]. 
Rudzkie Beds

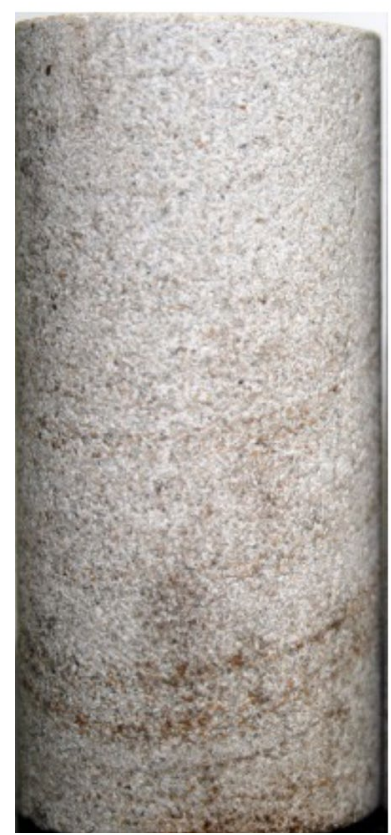

Laziskie Beds

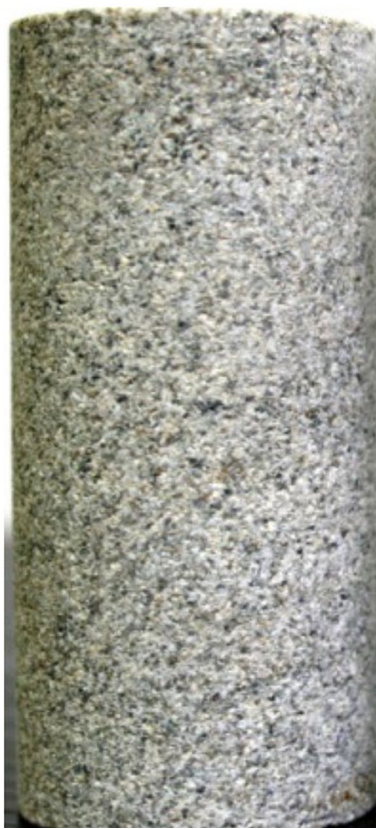

Fig. 1 Exemplary samples prepared for uniaxial compression tests: on the left the very fine-grained sandstone-Rudzkie Beds; on the right: the medium-grain sandstone—_aziskie Beds

The values of uniaxial compressive strength (UCS) and Young's modulus were determined. For each of the investigated temperatures the tests were carried out on a series of a 3 or 4 samples and the resultant geomechanical parameters were evaluated as the mean values.

\subsection{Micro-scale experiments}

The micro-scale investigation was carried out in the Faculty of Civil Engineering of the Wroclaw University of Science and Technology, Poland. As mentioned above, two different laboratory techniques were used. These are presented in details in subsequent Sections.

\subsubsection{X-Ray micro-computed tomography}

The X-ray micro-computed tomography is a non-destructive technique that enables the visualization of the internal microstructure of the material being examined. The principle of the tomography is illustrated in Fig. 4, while detailed description can be found e.g. in [30]. The resultant three-dimensional (3D) image of the structure can be quantitatively and qualitatively analysed using image analysis techniques.

Due to the high density of the tested rock material, it was necessary to significantly reduce the size of the samples. In the presented research, the sandstone was trimmed to the required size (cuboid with dimensions $3 \times 3 \mathrm{~mm}$ in the cross section and minimum height of $10 \mathrm{~mm}$ ) with the use of a high-speed precision saw Struers Labotom-5. The samples prepared for the tomography are presented in Fig. 5.

The Bruker Skyscan 1172 scanner (Fig. 6) with a conical radiation beam was used. The device is equipped with a $\mathrm{X}$-ray source with a maximum voltage of $100 \mathrm{kV}$ and power of $10 \mathrm{~W}$. The projection images were acquired with a resolution of $4000 \times 2667$ pixels.

To avoid artefacts and to obtain the required contrast between the individual components of the microstructure,

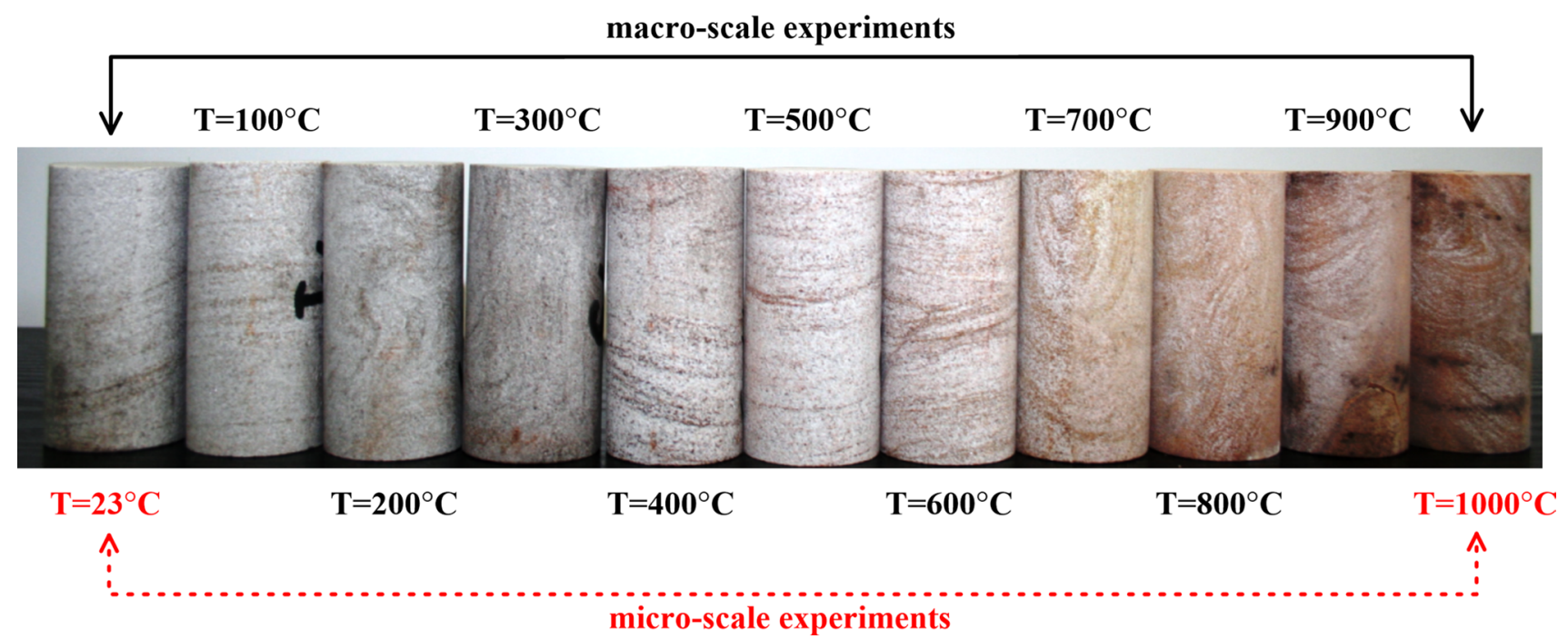

Fig. 2 Scheme of the investigation programme (the very fine-grained sandstone) 


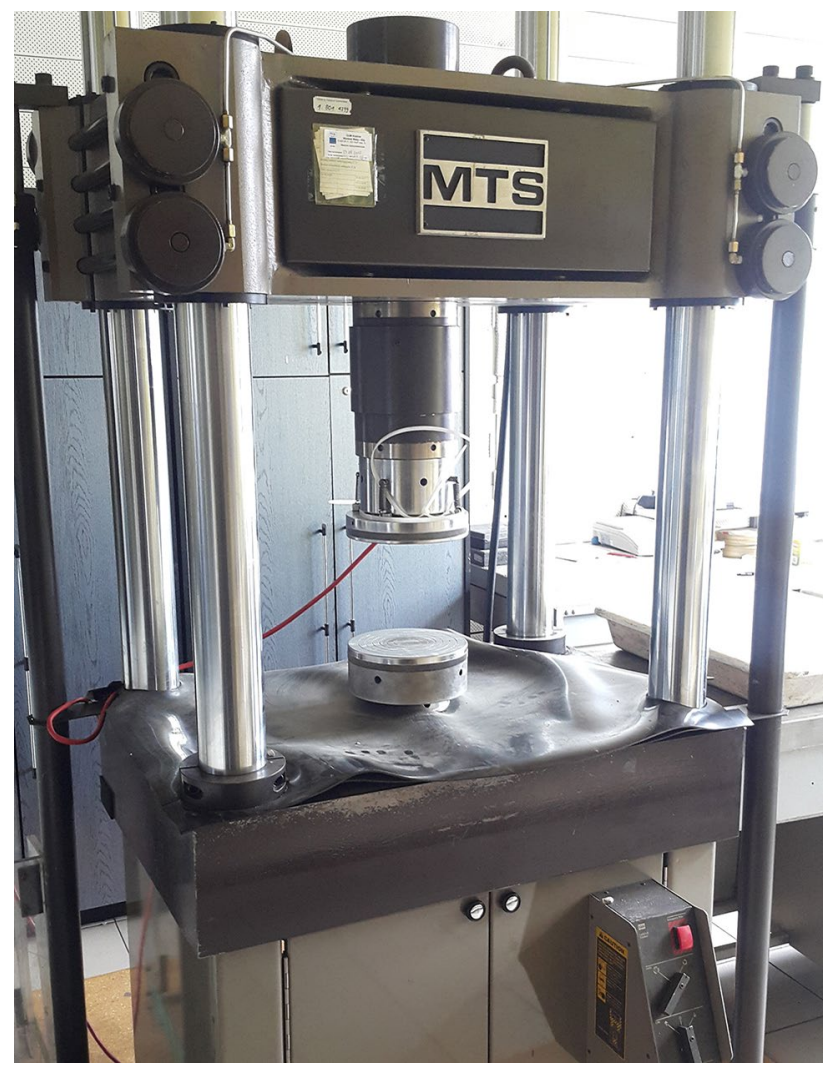

Fig. 3 Servo-controlled testing machine MTS-810 used for mesoscale investigation

appropriate scanning parameters (Table 1) were selected based on preliminary scans.

For the obtained projections set the NRecon software based on the Feldkamp algorithm [31,32] was used for
$3 \mathrm{D}$ reconstruction. The set of reconstruction parameters is shown in Table 2 .

\subsubsection{Nanoindentation tests}

The nanoindentation test involves pressing a rigid indenter of known geometry and known mechanical parameters into the surface of the material being tested. As a result a contact surface is formed between the tip of the indenter and the material [33]. Typical test runs as follows: continuous increase of force up to a fixed value, $F_{\max }$, then a short period in which the maximum value of force is maintained, after that it is followed by unloading which is also carried out continuously (Fig. 7a). During the test, the relation between the indentation force $F$ and the depth of penetration $h$ is recorded. An example of $F-h$ curve, obtained for a single test, is presented in Fig. 7b.

From a single nanoindentation test two parameters are typically determined, i.e. hardness $H_{\mathrm{IT}}$-defined as follows:

$H_{\mathrm{IT}}=\frac{F_{\max }}{A}$,

and indentation modulus $M_{\mathrm{IT}}$ expressed as:

$M_{\mathrm{IT}}=\frac{S}{2 \beta} \frac{\sqrt{\pi}}{\sqrt{A}}$

In the equations above, $F_{\max }$ is the maximum force of indentation, $A$ is the projection of the contact area on the surface of the sample - this value is usually defined as a function of the maximum indentation depth $h_{\max }$ [34] and $S$ is the initial slope of the unloading curve (see Fig. 7b). Equation (2) is a consequence of a well-known solution describing the pressing of a rigid, axisymmetric element
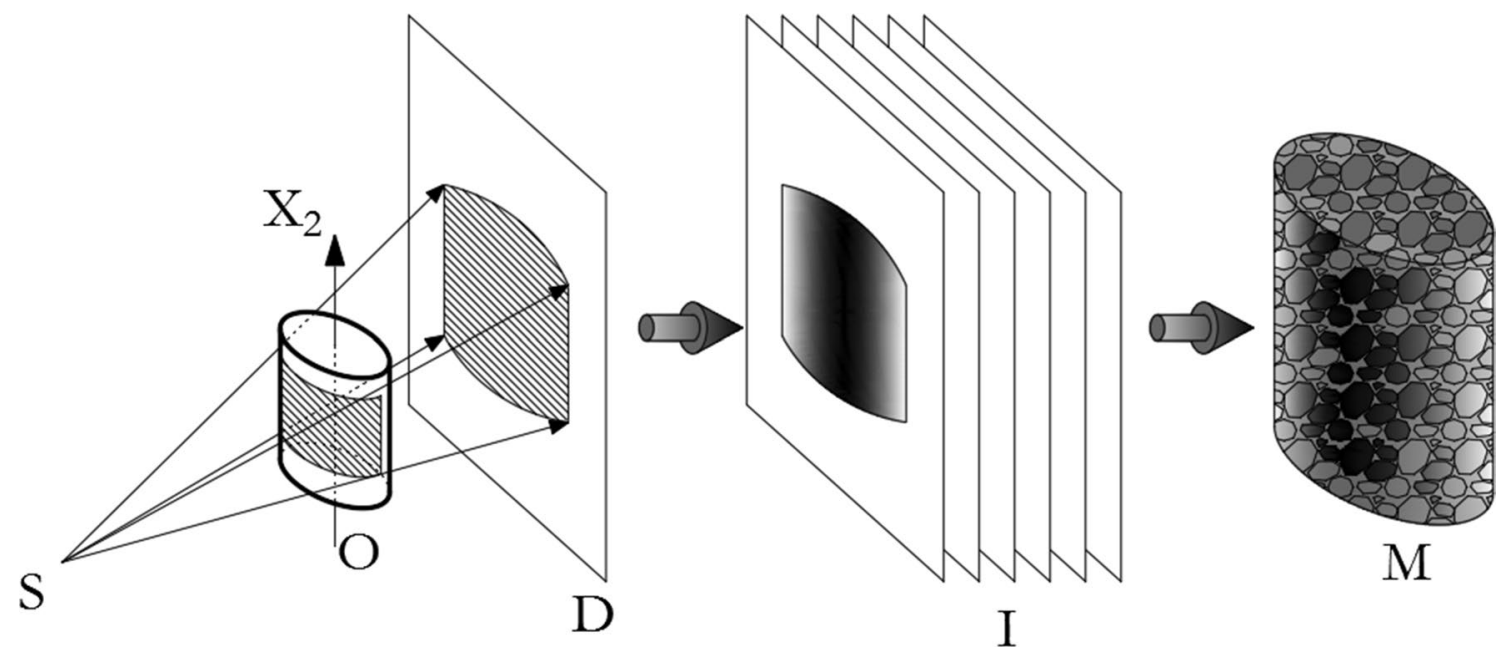

Fig. 4 Scheme of the tomography: $\mathrm{S}$-radiation source, $\mathrm{O}$ - scanned object, $\mathrm{X}_{2}$-axis of the object rotation, D-detector, I-acquisition of a series of projections, $\mathrm{M}-$ microstructure reconstruction 


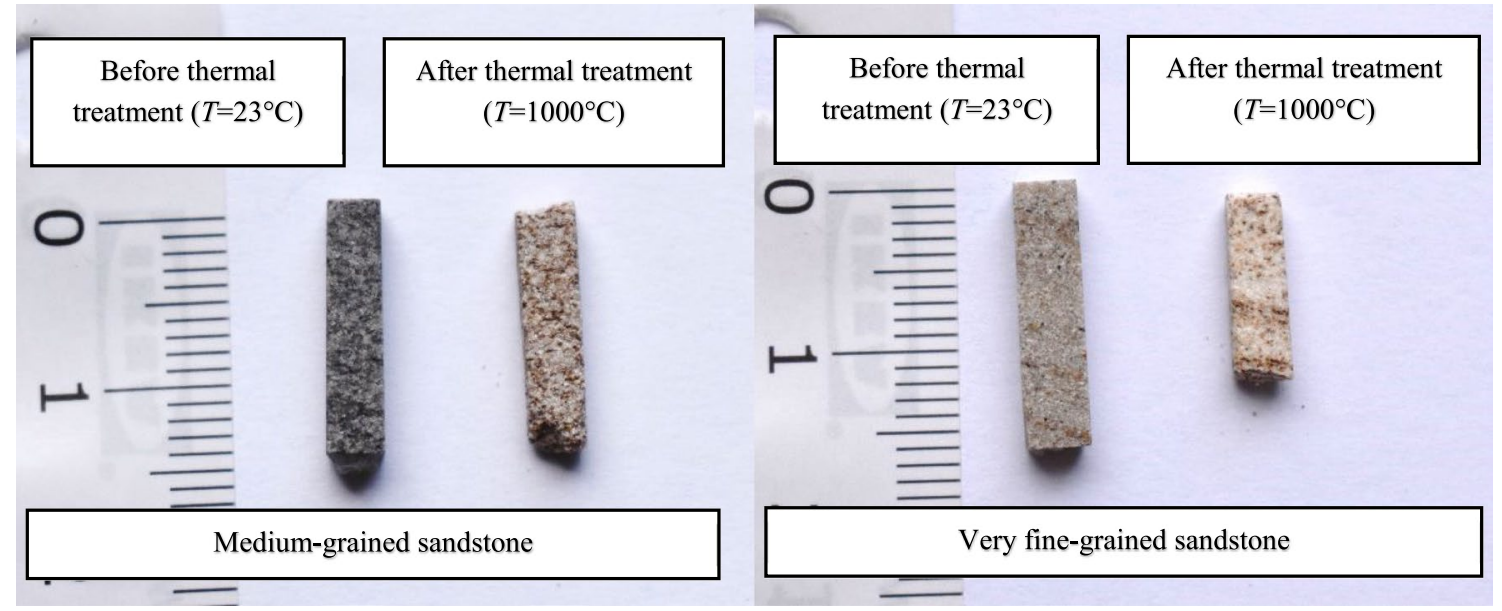

Fig. 5 The samples of sandstones prepared for micro-computed tomography imaging

Fig. 6 View of the Bruker Skyscan 1172 scanner and zoom on the sandstone specimen

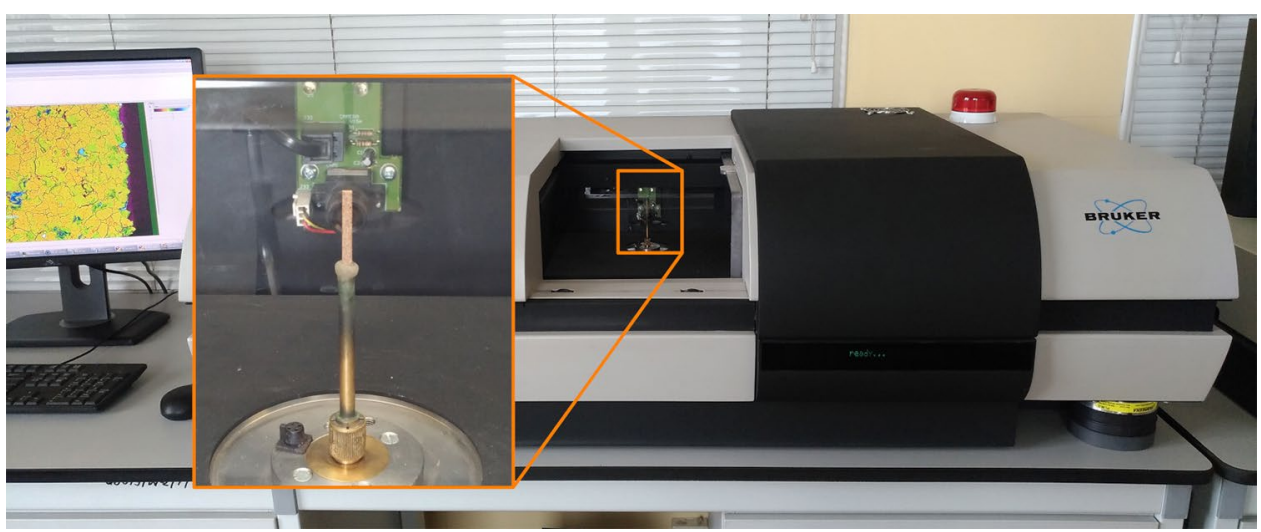

Table 1 Selected scanning parameters

\begin{tabular}{ll}
\hline Parameter & Value \\
\hline Source voltage $(\mathrm{kV})$ & 55 \\
Source current $(\mu \mathrm{A})$ & 181 \\
Image pixel size $(\mu \mathrm{m})$ & 1.69 \\
Filter & $\mathrm{Al} 0.5 \mathrm{~mm}$ \\
Exposure $(\mathrm{ms})$ & 1600 \\
Rotation step $(\mathrm{deg})$ & 0.180 \\
Frame averaging & $\mathrm{ON}(6)$ \\
Random movement & $\mathrm{ON}(10)$ \\
Use 360 rotation & YES \\
Geometrical correction & ON \\
\hline
\end{tabular}

into an elastic half-space [35]. The presence of the coefficient $\beta$ in this equation is due to the necessity to include, in the original Sneddon's solution, corrections resulting from the indenter geometry and large deformations [36]. In
Table 2 Selected reconstruction parameters

\begin{tabular}{ll}
\hline Parameter & Value \\
\hline Post alignment & -16 \\
Pixel size $(\mu \mathrm{m})$ & 1.692 \\
Object larger than FOV & OFF \\
Ring artefact correction & 11 \\
Beam hardening correction $(\%)$ & 20 \\
Threshold for defect pixel mask $(\%)$ & 0 \\
CS Static rotation (deg) & 94.26 \\
Minimum for CS to image conversion & 0.000 \\
Maximum for CS to image conversion & 0.18 \\
\hline
\end{tabular}

this work the CSM TTX-NHT nanoindenter equipped with a Berkovich tip (Fig. 8) was used. This implies that the coefficient $\beta$ is equal to 1.034 . The mechanical parameters of the diamond tip are as follows: Poisson's ratio $\nu_{\mathrm{i}}=0.07$ and modulus of elasticity $E_{\mathrm{i}}=1000 \mathrm{GPa}$.

It is obvious that investigated sandstones are micro-heterogeneous materials. This implied the necessity to utilise 
the Grid Indentation Technique (GIT) which was originally proposed by Constantinides et al. [37] for cementitious materials testing. Hence, for each rock sample, 800 individual nanoindentation tests were performed on two pre-defined regular grids (400 measurements each). The distance between grid points was selected on the basis of the preliminary nanoindentations providing that there is no interaction between the successive tests. Finally, the distance between the individual indentations (in both directions) was assumed as $100 \mu \mathrm{m}$ (Fig. 9).

An important remark is that nanoindentation tests were preceded by the appropriate and time-consuming process of specimen preparation. The Struers CitoVac vacuum chamber and the Struers LaboPol-5 grinder were used for the sample preparation. The photos of the rock pieces immersed in epoxy resin to be tested in the nanoindenter are shown in Fig. 10.

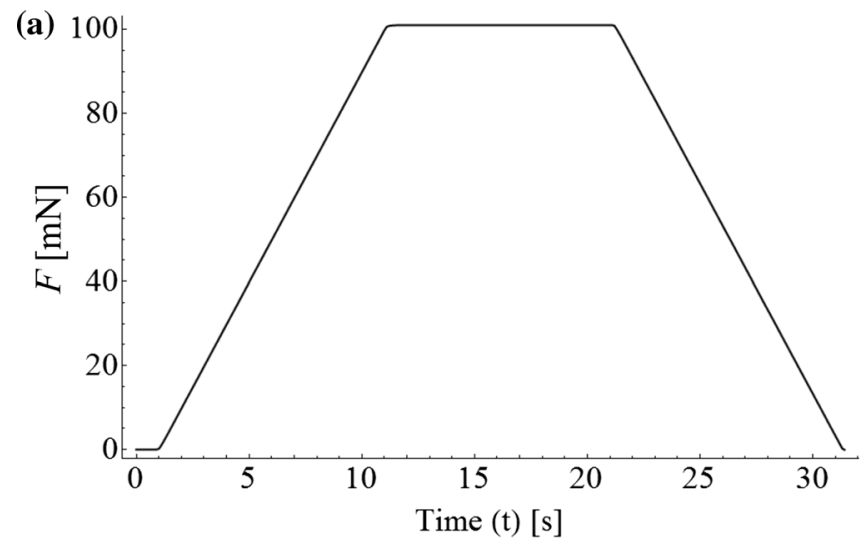

\section{Results}

\subsection{Meso-scale experiments}

As mentioned the meso-scale experiments were carried out for the series of sandstones at all considered nominal temperature values (see Fig. 2). Four exemplary stress-strain curves, obtained from uniaxial compression tests, are shown in Fig. 11. Presented results correspond to both sandstones at two extreme cases: $T=23^{\circ} \mathrm{C}$ and $T=1000{ }^{\circ} \mathrm{C}$.

The variability of mean values of both uniaxial compressive strength (UCS) and Young's modulus as a function of temperature are shown in Figs. 12 and 13, respectively. It is possible to observe certain temperature ranges in which the mechanical characteristics of the rock material changes. These ranges differ for both types of sandstone. In the case of medium-grained sandstone (apart from small variations), it can be assumed that up to a temperature of $700{ }^{\circ} \mathrm{C}$ the mean value of UCS increases, however, after exceeding this temperature, UCS decreases. For the temperature of $1000{ }^{\circ} \mathrm{C}$, the mean value of uniaxial compressive strength is higher than that determined for the reference temperature,

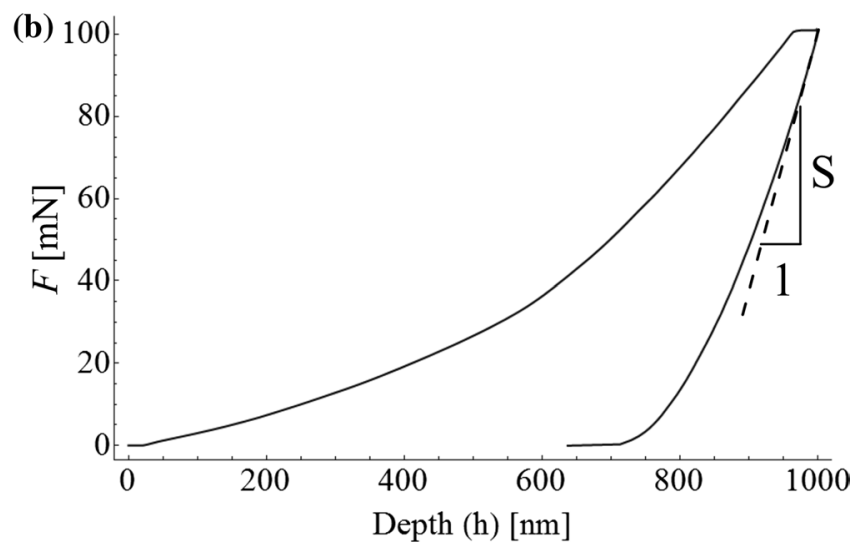

Fig. 7 a Load function $F(t)$ in nanoindentation test; $\mathbf{b}$ example of $F-h$ curve
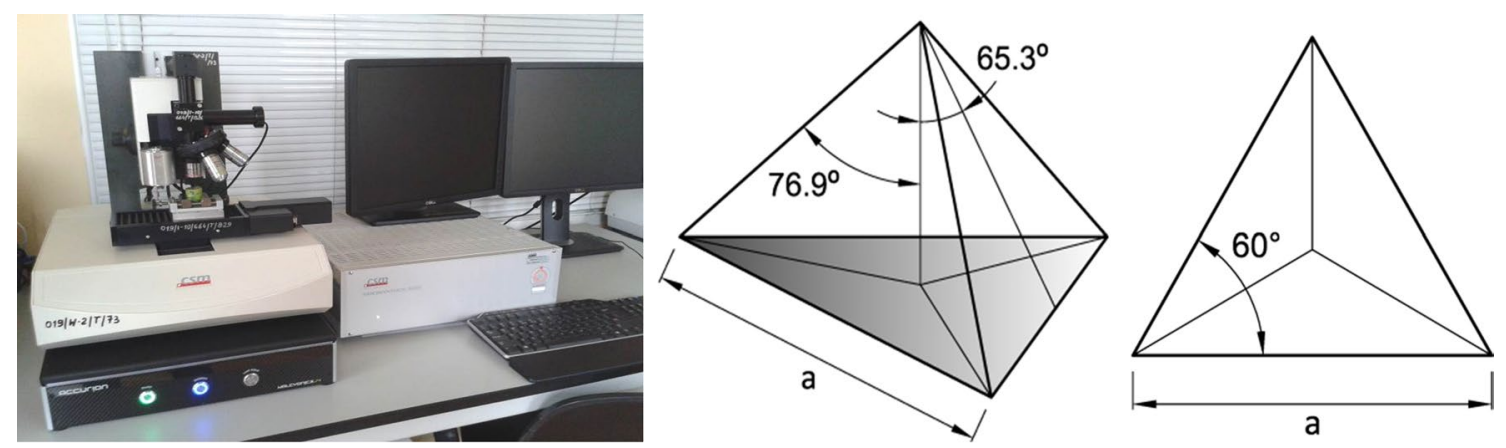

Fig. 8 Nanoindenter CSM TTX-NHT and a geometry of the Berkovich tip used in the research 


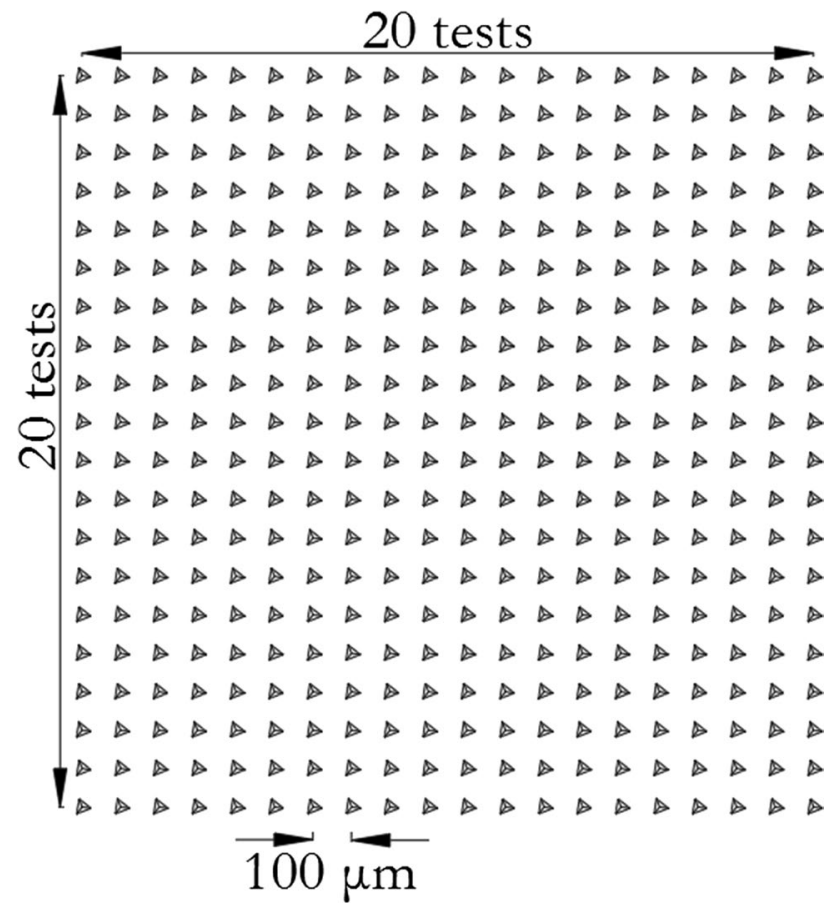

Fig. 9 Indentation grid

i.e. of $23{ }^{\circ} \mathrm{C}$. In the case of the very fine-grained sandstone this characteristic is similar. Nevertheless, the change in the trend (from increase to decrease) of the 'UCS vs. temperature' curve occurs within the rage of temperature 200-300 ${ }^{\circ} \mathrm{C}$. In addition, at the temperature of $1000{ }^{\circ} \mathrm{C}$ "weakening" of the rock material is observed-the mean value of uniaxial compressive strength is clearly lower than that determined at $23{ }^{\circ} \mathrm{C}$.

The mean values of Young's modulus with increasing temperature (Fig. 13) change similarly to the uniaxial compressive strength. The stiffness increases up to a certain temperature value (very fine-grained sandstone-approx. $200{ }^{\circ} \mathrm{C}$, medium-grained sandstone-approx. $400{ }^{\circ} \mathrm{C}$ ), while for higher temperatures a noticeable decrease in the mean value of Young's modulus can be observed. At the temperature of $1000{ }^{\circ} \mathrm{C}$, both sandstones are characterized by lower values of Young's modulus compared to those determined for the ambient temperature $\left(23^{\circ} \mathrm{C}\right)$.

Interesting results can be observed if the ratio between stiffness and the strength (E/UCS) is plotted against temperature values (Fig. 14). Note that while there are some differences in the behaviour of both sandstones due to the variability of $E$ modulus and strength (in uniaxial compression-UCS) with temperature (Figs. 12 and 13), the ratio E/UCS reveals similar course for both rocks, i.e., up to the temperature of $100{ }^{\circ} \mathrm{C}$ there is a sudden increase in the value of the E/UCS ratio, and then a decrease in its value up to the temperature of about $700{ }^{\circ} \mathrm{C}$. After exceeding this value of temperature $\left(700^{\circ} \mathrm{C}\right), \mathrm{E} / \mathrm{UCS}$ is almost constant.
Fig. 10 Pieces of sandstones immersed in epoxy resin to be used in nanoindentation tests: the very fine-grained sandstone on the left and the mediumgrained sandstone on the right
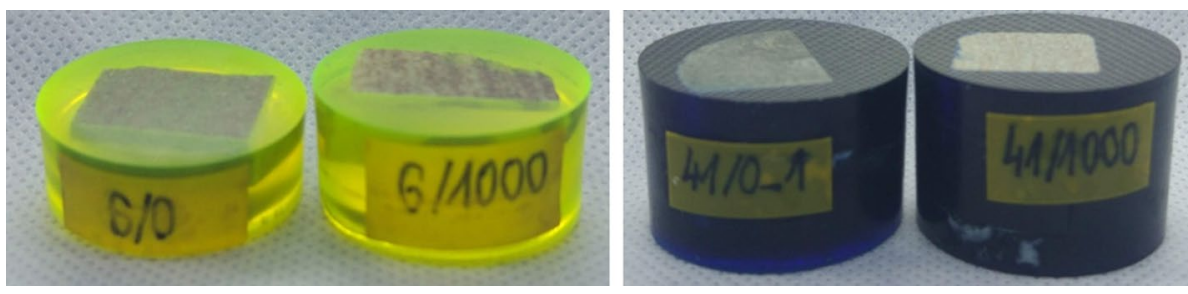

Fig. 11 Selected stress-strain curves for sandstones at two extreme temperature values

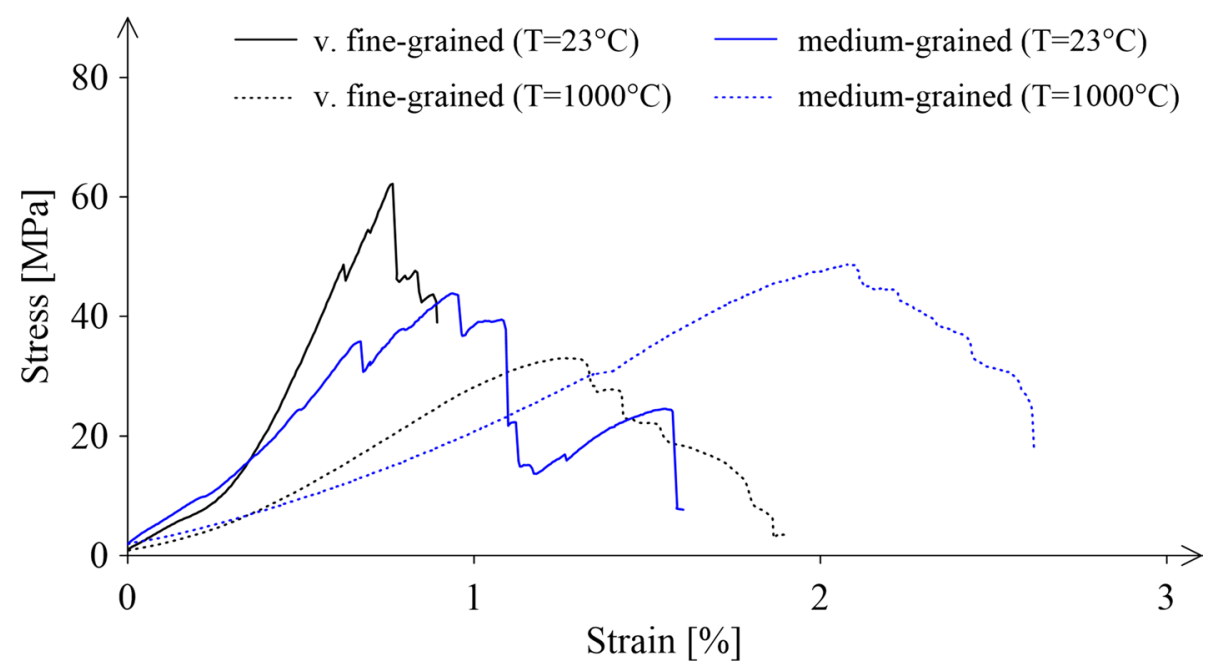


Fig. 12 Mean values of uniaxial compressive strength as a function of temperature
Fig. 13 Mean values of the Young's modulus as a function of temperature
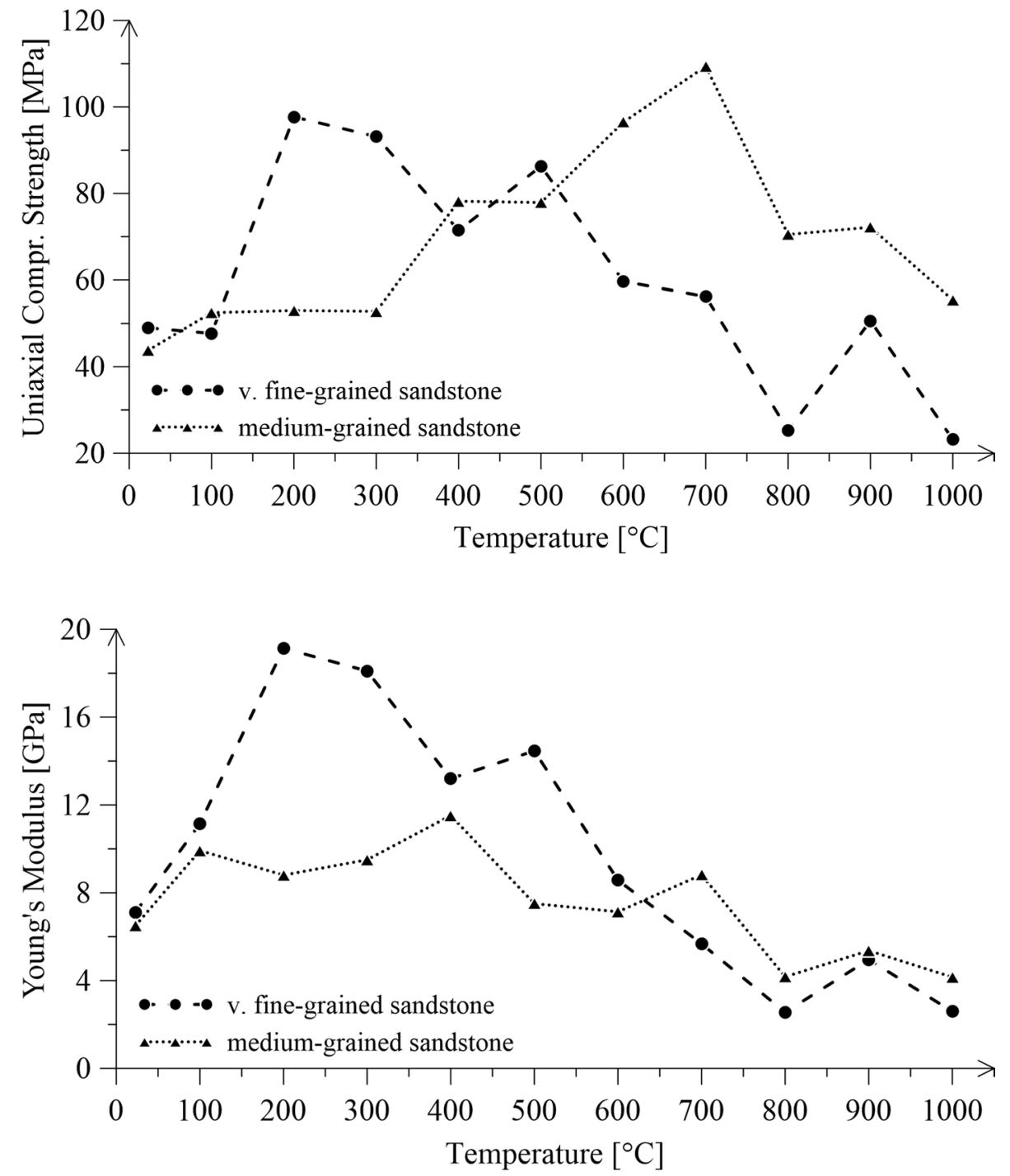

\subsection{Micro-scale experiments}

\subsubsection{X-Ray micro-computed tomography}

Rendered views of reconstructed 3D images of the scanned samples are shown in Figs. 15 (very fine-grained sandstone) and 16 (medium-grained sandstone). In both figures the reference sample (air-dried state, $23{ }^{\circ} \mathrm{C}$ ) is shown on the left, whereas the one treated with high temperature $\left(1000^{\circ} \mathrm{C}\right)$ on the right.

The analyses of the microstructure of the tested rock materials were performed within so called volume of interest (VOI). For all samples the VOI was selected as a cubic sub-volume containing $1600^{3}$ voxels (what corresponds to $2.707^{3} \mathrm{~mm}^{3}$ ) of the reconstructed 3D image. Each VOI was entirely contained in the tested material (Figs. 17 and 18).

The histograms of grey level values within the VOI (after applying a smoothing filter) are presented in Figs. 19 and 20.
To show how the distribution of the grey value evolved with high-temperature treatment, the histograms are presented together in the same plot displayed by different colours: pink (reference temperature $23{ }^{\circ} \mathrm{C}$ ) and grey (temperature $1000{ }^{\circ} \mathrm{C}$ ).

Figures 21 and 22 present the microstructure of the sandstones in horizontal cross-section located in the centre of the VOI height. Observing zoom of the cross-section it can be concluded that cracks appeared on the inter-grain contacts as a result of high-temperature treatment.

To perform morphometric analysis and to assess how the pore space evolves due to high temperature, a segmentation was carried out by global thresholding. The pixels characterized by the grey value between 0 and 47 are assigned to pores (black in the binary image) and the remaining ones (grey values $48-255$ ) to the solid phase (white in the binary image). The results of segmentation are shown in Figs. 23 
Fig. 14 Mean values of E/UCS ratio as a function of temperature

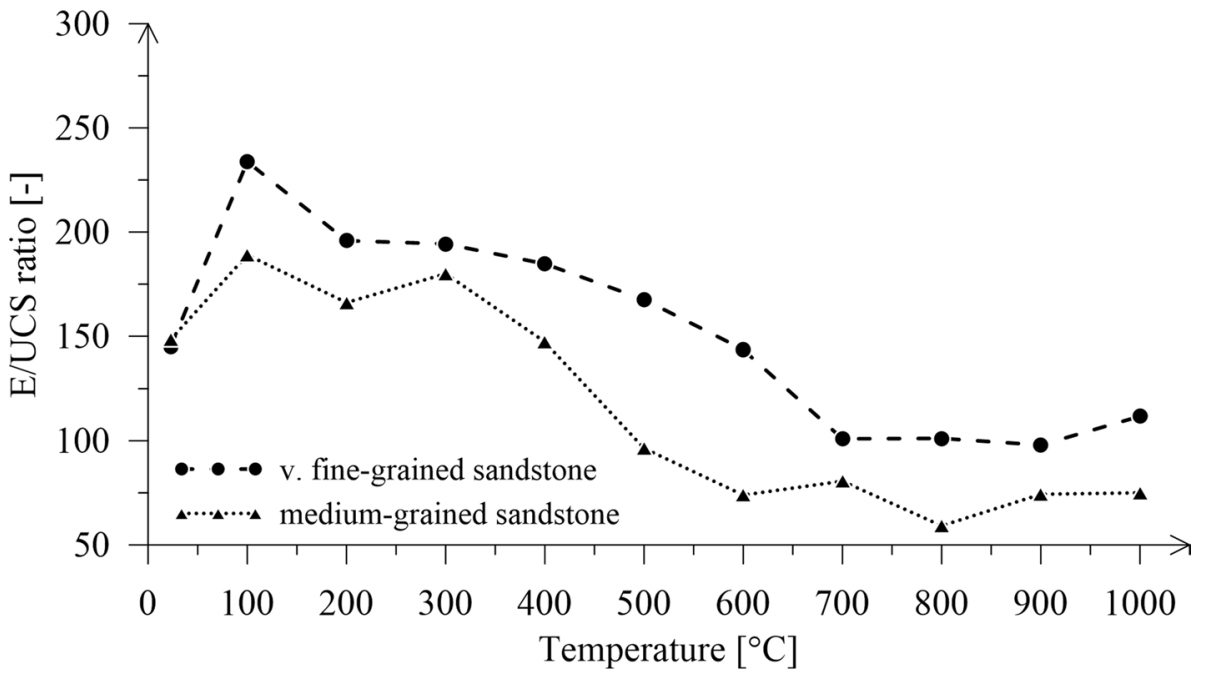

(a)

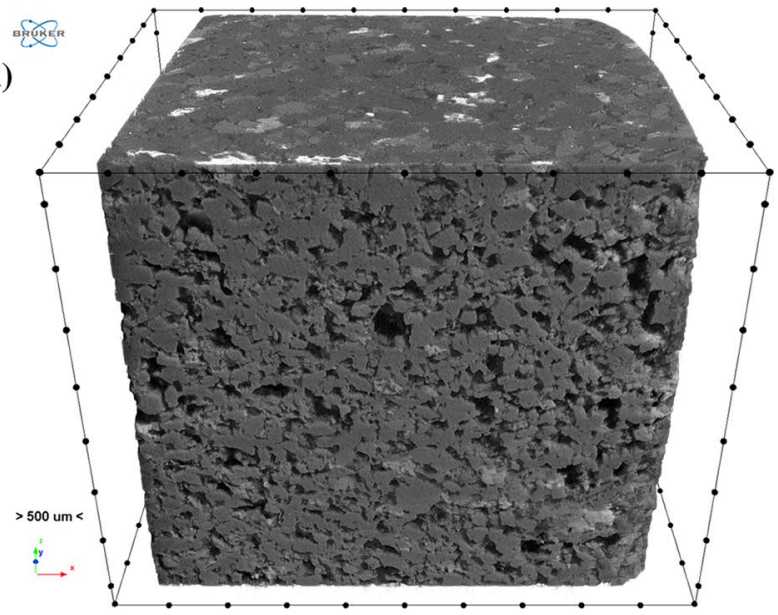

(b)

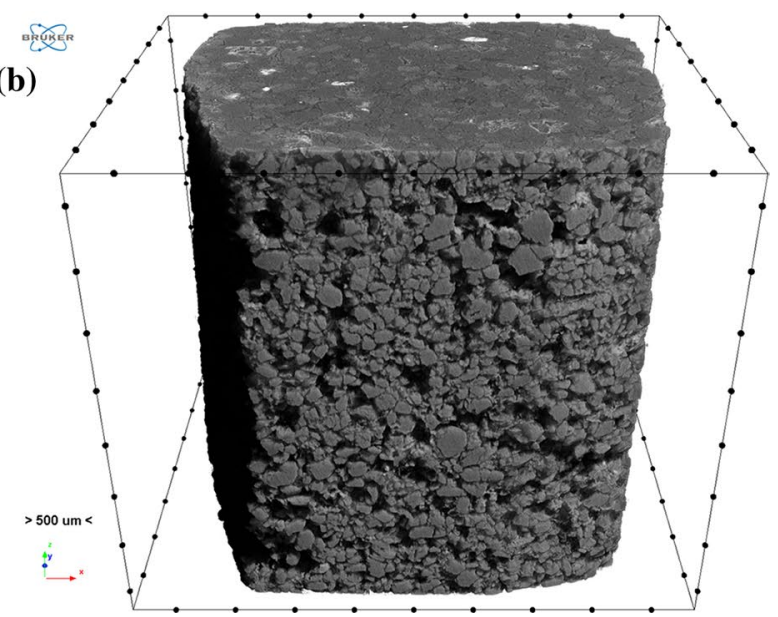

Fig. 15 Reconstruction of the very fine-grained sandstone-3D view: a reference sample $T=23{ }^{\circ} \mathrm{C}$, b sample after high-temperature treatment $T=1000{ }^{\circ} \mathrm{C}$

and 24, for the same cross-sections as presented previously in Figs. 21 and 22.

Using 3D binary model the following microstructural measures were calculated, i.e., the volume fraction of the voids (porosity), specific surface and the spatial distribution of local pore thickness. The first of these measures is defined as the number of voxels belonging to the pores divided by the total number of voxels in the VOI. The specific surface is defined as the estimated area of the interface (pores and solids) related to the volume of the VOI. Local structure thickness [38] is a scalar field defined only in the area occupied by the considered constituent (pores). In general, the procedure for determining pore local thickness consists in filling the area occupied by pores with spheres with the possibly largest diameter. Then the local thickness in a given point $\boldsymbol{x}$ is defined as the largest diameter of the sphere, which is fully contained in the pore space and at the same time contains point $\boldsymbol{x}$ [39]. The calculated values (porosity, specific surface and the mean of the local thickness) are presented in Table 5, which is provided in the section entitled "Discussion of results". The 3D distributions of pore local thickness are presented in Figs. 25 and 26, whereas the corresponding histograms are shown in Figs. 27 and 28.

\subsubsection{Nanoindentation tests}

The values of indentation modulus $M_{\mathrm{IT}}$ and hardness $H_{\mathrm{IT}}$ obtained for rock samples before and after heating at the nominal temperature of $1000{ }^{\circ} \mathrm{C}$-are presented in the form of histograms in Figs. 29 and 30. The results corresponding to the case of high-temperature heating $\left(1000{ }^{\circ} \mathrm{C}\right)$ were displayed in grey. Red and blue colours are corresponding to the results obtained for reference samples $\left(23{ }^{\circ} \mathrm{C}\right)$; red colour represents the distribution of the indentation modulus, 

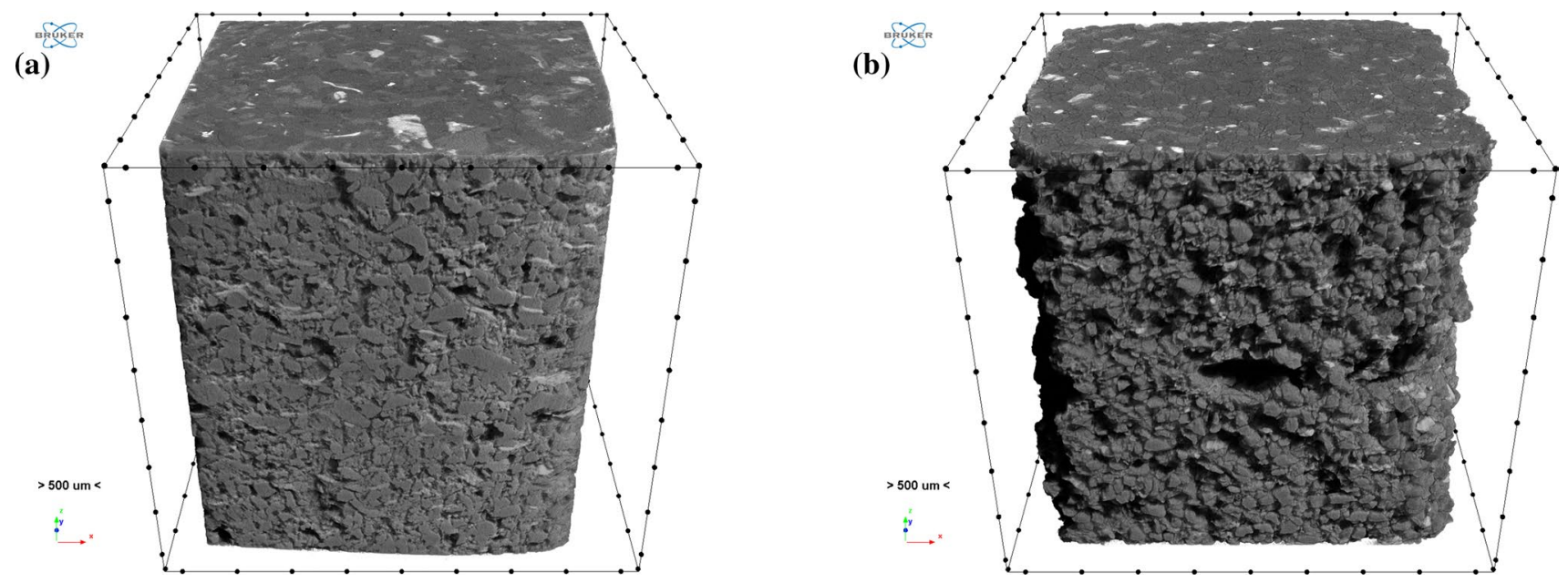

Fig. 16 Reconstruction of the medium-grained sandstone-3D view: a reference sample $T=23{ }^{\circ} \mathrm{C}, \mathbf{b}$ sample after high-temperature treatment $T=1000{ }^{\circ} \mathrm{C}$

(a)

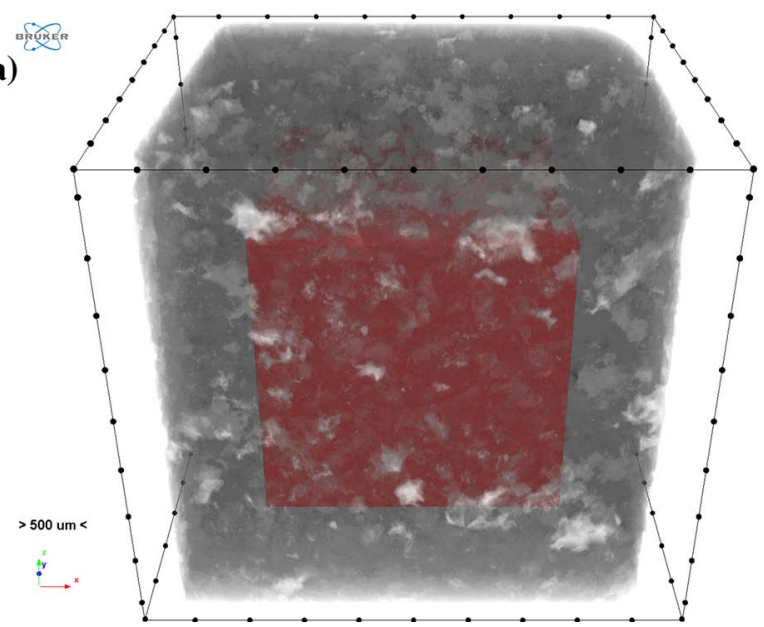

(b)

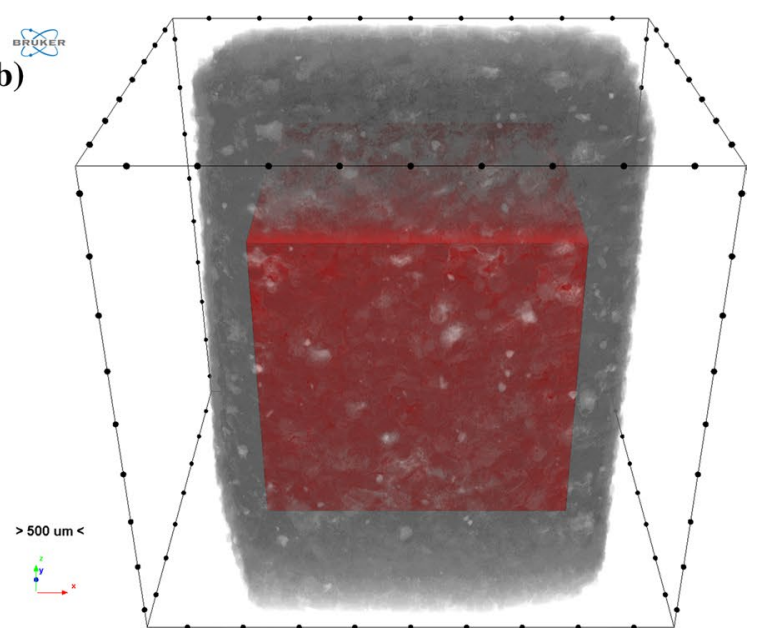

Fig. 17 VOI selection for the very fine-grained sandstone-3D view: a reference sample $T=23{ }^{\circ} \mathrm{C}$, $\mathbf{b}$ sample after high-temperature treatment $T=1000^{\circ} \mathrm{C}$

whereas the blue one represents the frequency of hardness values. The vertical dashed lines refer to the mean values calculated on the basis of all 800 individual nanoindentations. In particular, Fig. 29 shows the results obtained for the very fine-grained sandstone, while in Fig. 30 the results obtained for the medium-grained sandstone are presented. In addition, Table 3 summarizes the mean values $\mu$ and standard deviations $\sigma$ determined for all 800 independent nanoindentation tests.

Next, we aimed to determine-from the set of all the independent results - the averaged values of the mechanical parameters of the separated components. For that purpose the deconvolution technique was used (for detailed information regarding the deconvolution procedure the authors refer the reader to the work of [40]). Due to the lack of information on the mineralogical composition of the studied sandstones (such recognition is the subject of future works), the complex and multi-phase microstructure (obviously composed of many mineral components) of the tested material was replaced by two-phase microstructure with following constituents: 1 -clusters formed of mineral components characterized by relatively low microstructure strength, 2-clusters formed of mineral components with relatively high microstructure strength. As a consequence, the complex and multi-component morphology of the microstructure has been replaced by an equivalent two-component microstructure. It was assumed that the parameter reflecting the strength of the microstructure and, as a result, determining the segmentation into two individual components, is the hardness $H_{\mathrm{IT}}$. This is due to fact that, as shown in [41] and 
(a)

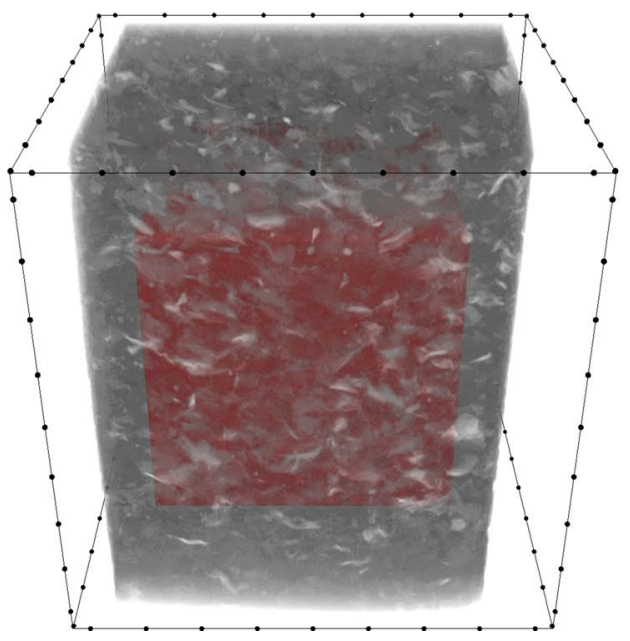

(b)

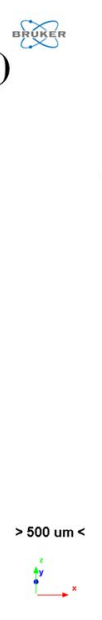

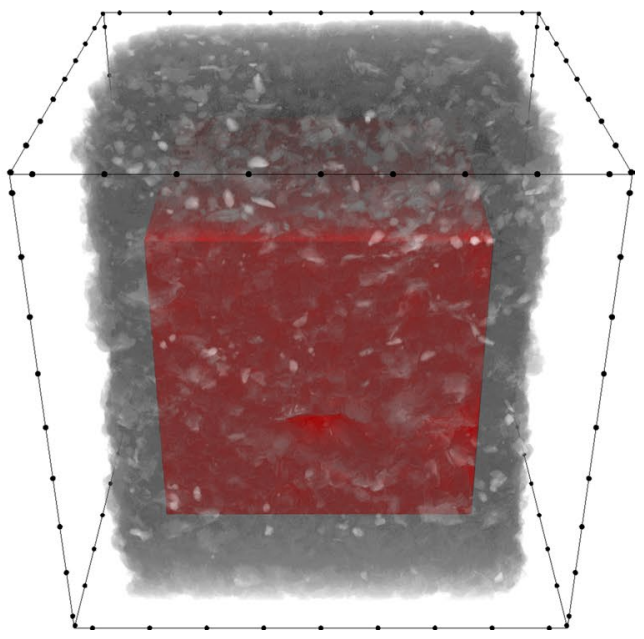

Fig. 18 VOI selection for medium-grained sandstone-3D view: a reference sample $T=23{ }^{\circ} \mathrm{C}$, b sample after high-temperature treatment $T=1000{ }^{\circ} \mathrm{C}$

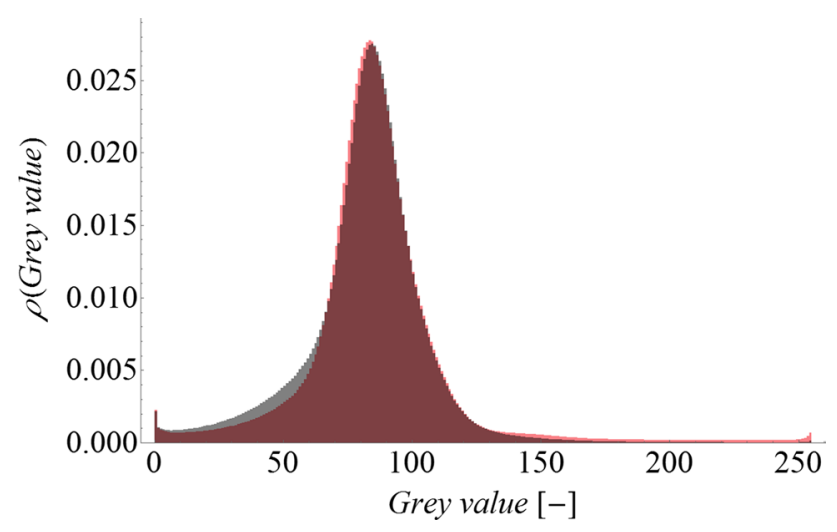

Fig. 19 Evolution of the histogram of grey value in VOI: the very fine-grained sandstone

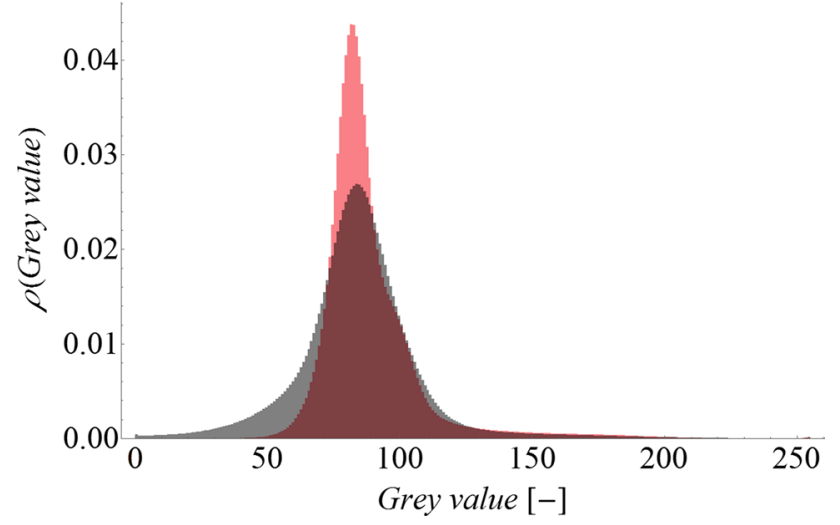

Fig. 20 Evolution of the histogram of grey value in VOI: the medium-grained sandstone
[42], the strength is proportional to the hardness of individual microstructure components-the higher the hardness the higher the strength of microstructure. Figures 31 and 32 show the results of deconvolution (segmentation into two components: 1 and 2) for hardness and indentation modulus, respectively. The dashed line represents the overall probability distribution function (pdf) - no segmentation applied (this is the pdf obtained for all 800 results). The two continuous lines show the probability densities determined for the separated components of the microstructure-after adopting the deconvolution technique with Gauss distributions.

Table 4 contains the parameters obtained for individual components as a result of deconvolution technique. In particular, the mean values of indentation moduli $\mu_{j}^{M_{\mathrm{TT}}}$ and hardness $\mu_{j}^{H_{\mathrm{IT}}}$ as well as the volume fractions $f$ of individual components are presented.

\section{Discussion of results}

As can be seen in Figs. 12, 13 and 14 the mean values of both meso-scale properties, i.e., Young's modulus and UCS show an evident evolution with respect to the temperature. However, although we refer to the mean values calculated from several (3-4) tests, which is the rule of thumb in this type of testing, the uncertainty of such measurement is large. Therefore, if we intended to utilize thermal treatment to improve rock mechanical parameters then the meso-scale testing could not be relied on, unless the changes in properties are evidently larger than the deviations from the mean values. For this reason, 

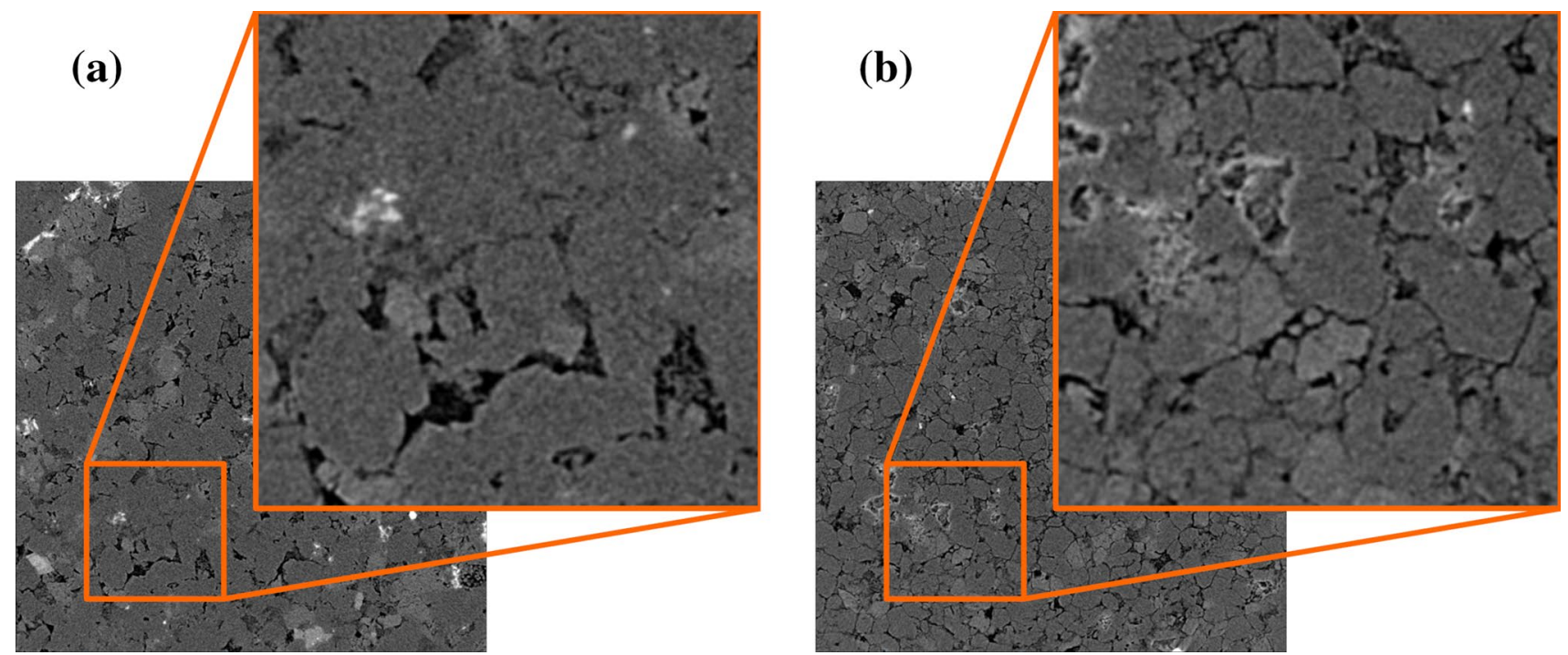

Fig. 21 Microstructure of the very fine-grained sandstone-cross-section view: a reference sample $T=23{ }^{\circ} \mathrm{C}, \mathbf{b}$ sample after high-temperature treatment $T=1000^{\circ} \mathrm{C}$
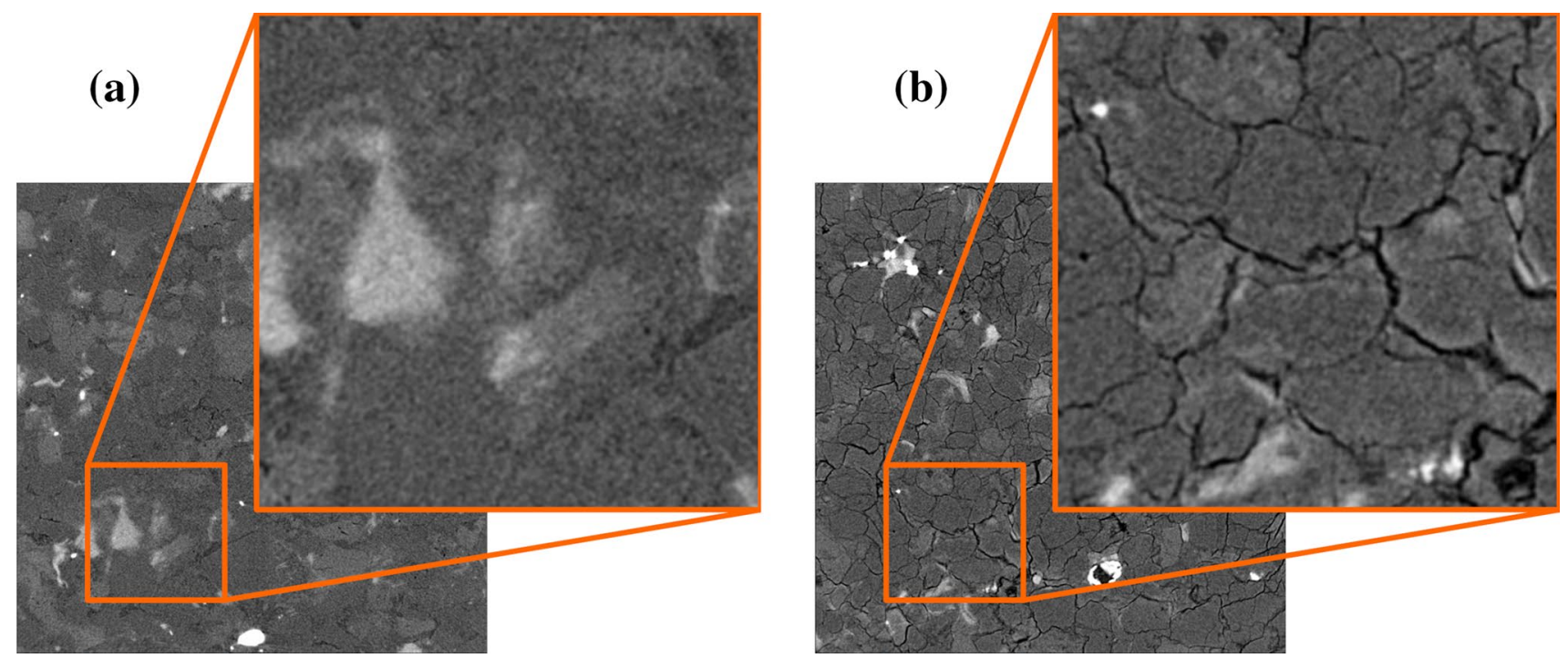

Fig. 22 Microstructure of the medium-grained sandstone-cross-section view: a reference sample $T=23{ }^{\circ} \mathrm{C}$, $\mathbf{b}$ sample after high-temperature treatment $T=1000{ }^{\circ} \mathrm{C}$

when developing the methodology of thermal treatment control, we decided to perform a research at micro-scale. In this case, it is possible to carry out several hundred or even several thousand individual tests for the same rock material. Such a large number of tests is sufficient (from a statistical point of view) to identify intrinsic changes in the material.

For the purpose of developing the methodology for identifying microstructural changes due to temperature treatment, the tests at the micro-scale were limited to two extreme cases of thermal treatment, i.e., a reference case of ambient temperature $T=23{ }^{\circ} \mathrm{C}$ and the highest of considered temperatures $T=1000{ }^{\circ} \mathrm{C}$. Therefore, further discussion concerns these two cases with respect to all testing techniques, i.e., uniaxial compression tests (meso-scale) as well as nanoindentation and micro-computed tomography (micro-scale). The results are summarized in Table 5.

In the case of uniaxial compression tests (meso-scale research), the following observations can be stated:

1. As a result of high-temperature treatment the transition from brittle to ductile behaviour is observed—see 

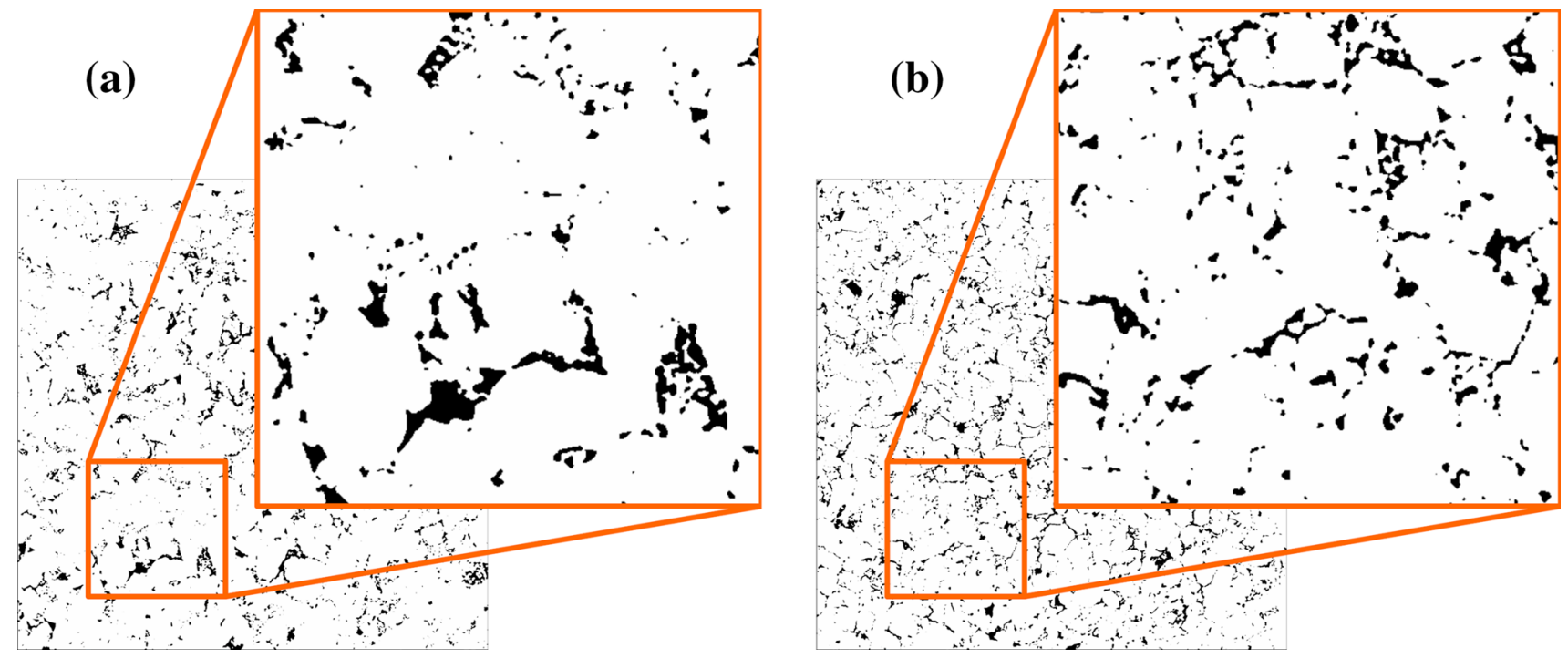

Fig. 23 Result of pore space segmentation in the very fine-grained sandstone-cross-section view: a reference sample $T=23{ }^{\circ} \mathrm{C}$, b sample after high temperature treatment $T=1000^{\circ} \mathrm{C}$
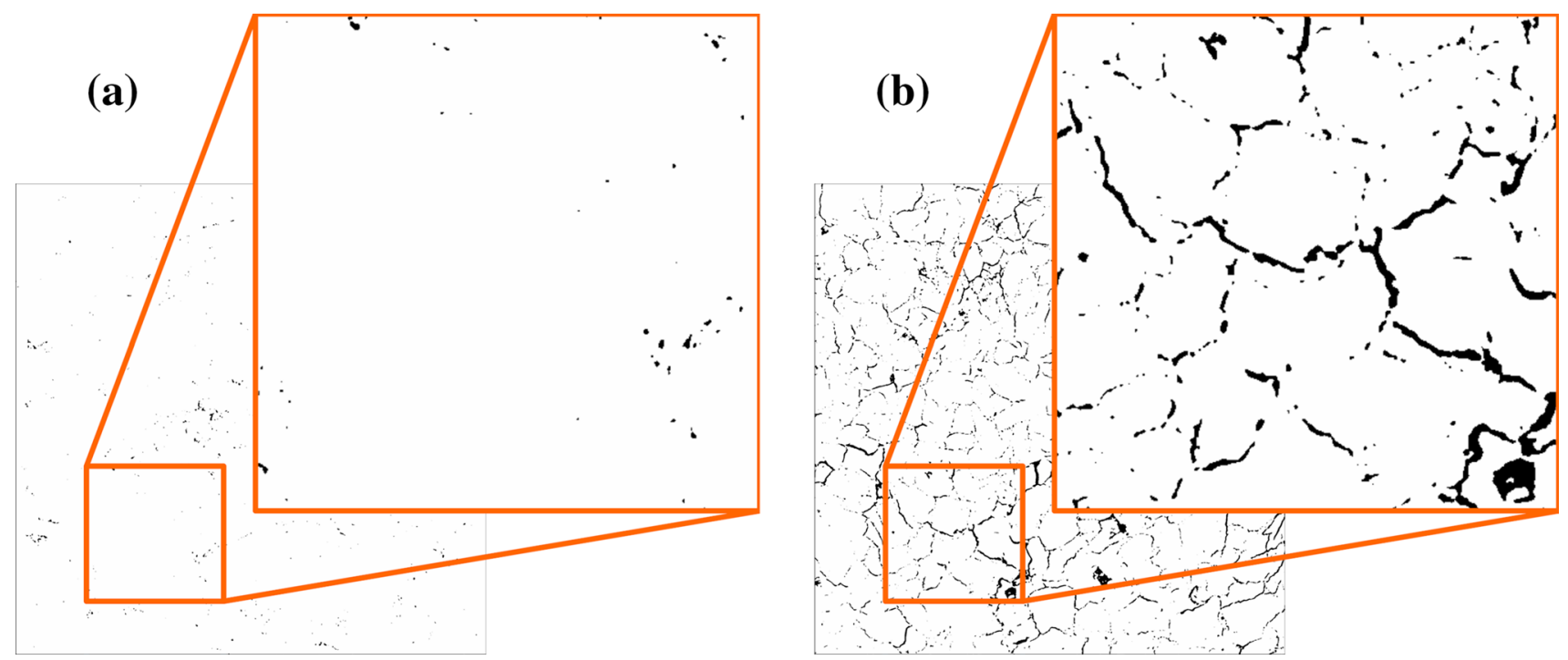

Fig. 24 Result of pore space segmentation in the medium-grained sandstone-cross-section view: a reference sample $T=23{ }^{\circ} \mathrm{C}$, b sample after high temperature treatment $T=1000{ }^{\circ} \mathrm{C}$

Fig. 11. Both sandstones tend to fail in a brittle manner prior to heating; 'stress-strain' characteristics exhibit sudden drops in stress value, the primary one just after the peak value of stress. On the other hand, the course of 'stress-strain' characteristics for sandstones after exposing them to temperature cycle is considerably smoother, indicating ductile behaviour of the material rather than the brittle one.

2. The mean value of Young's modulus of both sandstones significantly decreases under the effect of thermal treatment (with maximum value of $1000{ }^{\circ} \mathrm{C}$ ).
3. The mean value of uniaxial compressive strength, in the case of the very fine-grained sandstone, decreased by half due to high-temperature treatment. The behaviour of this property for the medium-grained sandstone-after exposure to the temperature of $1000{ }^{\circ} \mathrm{C}$-is different. In this case, the uniaxial compressive strength increased from 43.8 to 55.4 MPa. Hence, the strengthening of the medium-grained sandstone, as a result of thermal treatment, is observed.

4. The ratio E/UCS reveals similar course for both considered rocks-up to a temperature of $100{ }^{\circ} \mathrm{C}$ we observe 

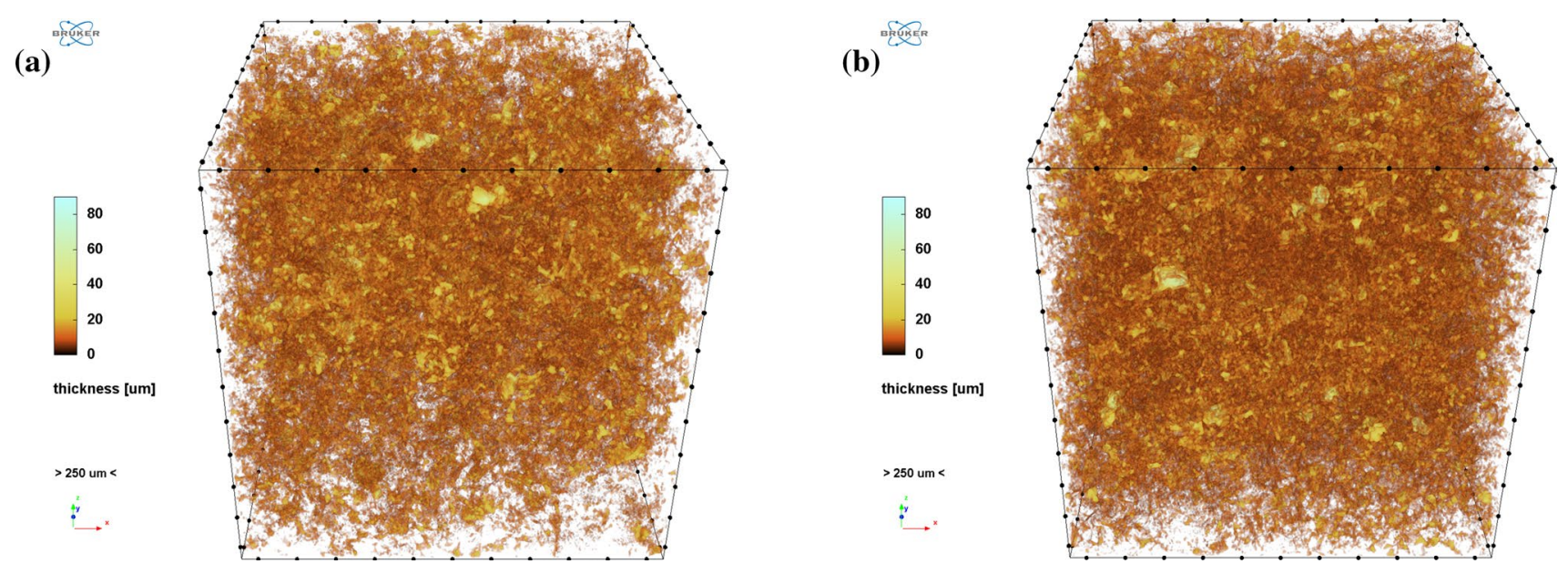

Fig. 25 Distribution of pore local thickness in the very fine-grained sandstone-3D view: a reference sample $T=23{ }^{\circ} \mathrm{C}, \mathbf{b}$ sample after high temperature treatment $T=1000{ }^{\circ} \mathrm{C}$
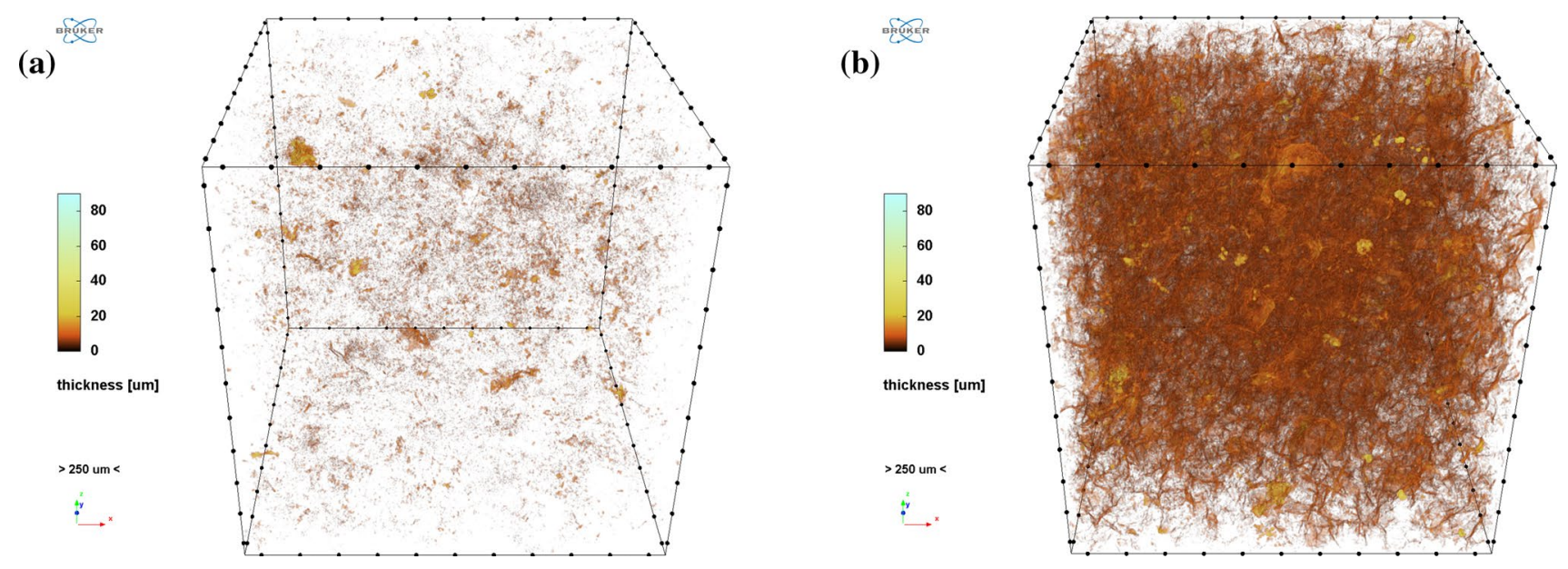

Fig. 26 Distribution of pore local thickness in the medium-grained sandstone-3D view: a reference sample $T=23^{\circ} \mathrm{C}, \mathbf{b}$ sample after high temperature treatment $T=1000{ }^{\circ} \mathrm{C}$
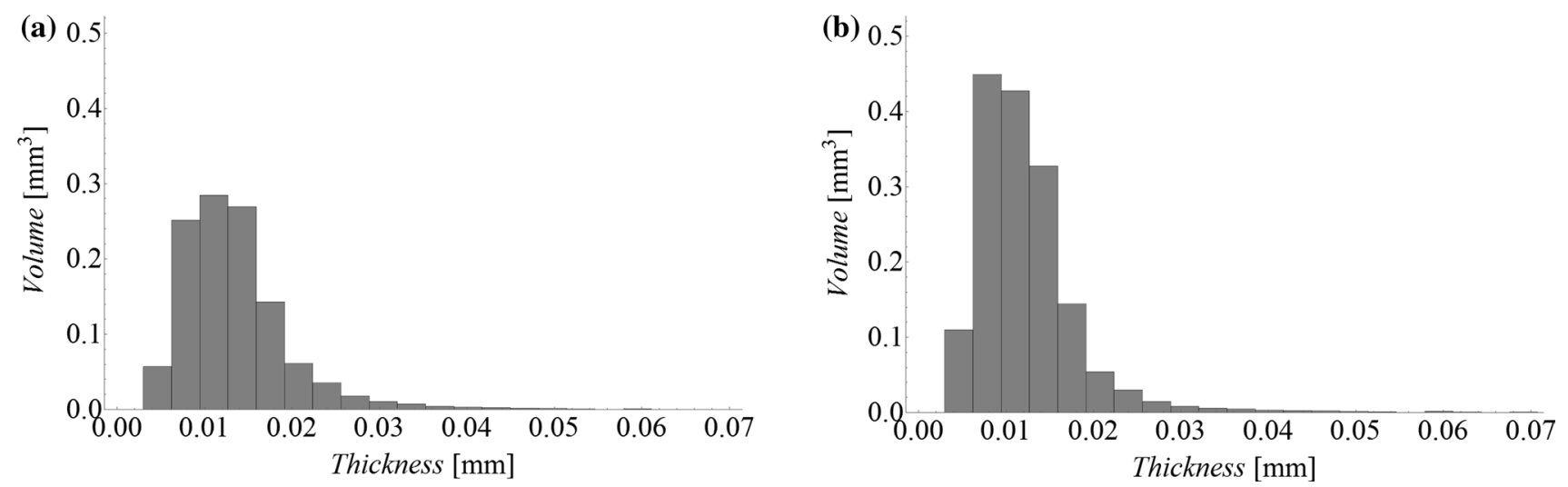

Fig. 27 Histogram of pore local thickness in the very fine-grained sandstone: a reference sample $T=23{ }^{\circ} \mathrm{C}$, b sample after high temperature treatment $T=1000{ }^{\circ} \mathrm{C}$ 

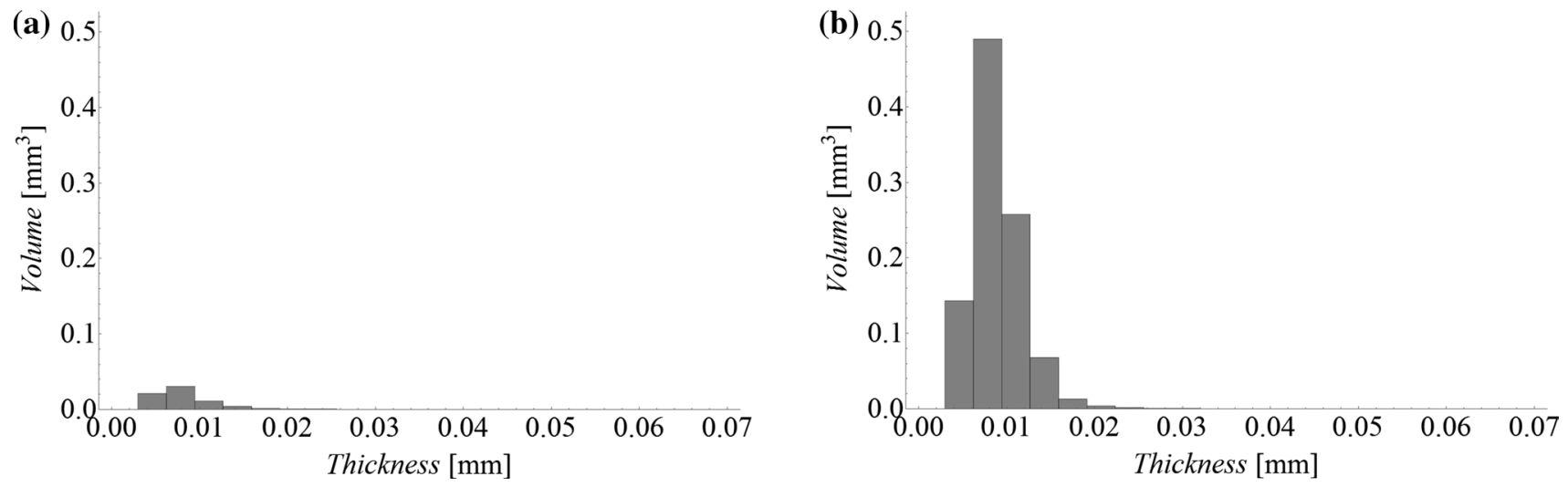

Fig. 28 Histogram of pore local thickness in the medium-grained sandstone: a reference sample $T=23{ }^{\circ} \mathbf{C}, \mathbf{b}$ sample after high temperature treatment $T=1000^{\circ} \mathrm{C}$
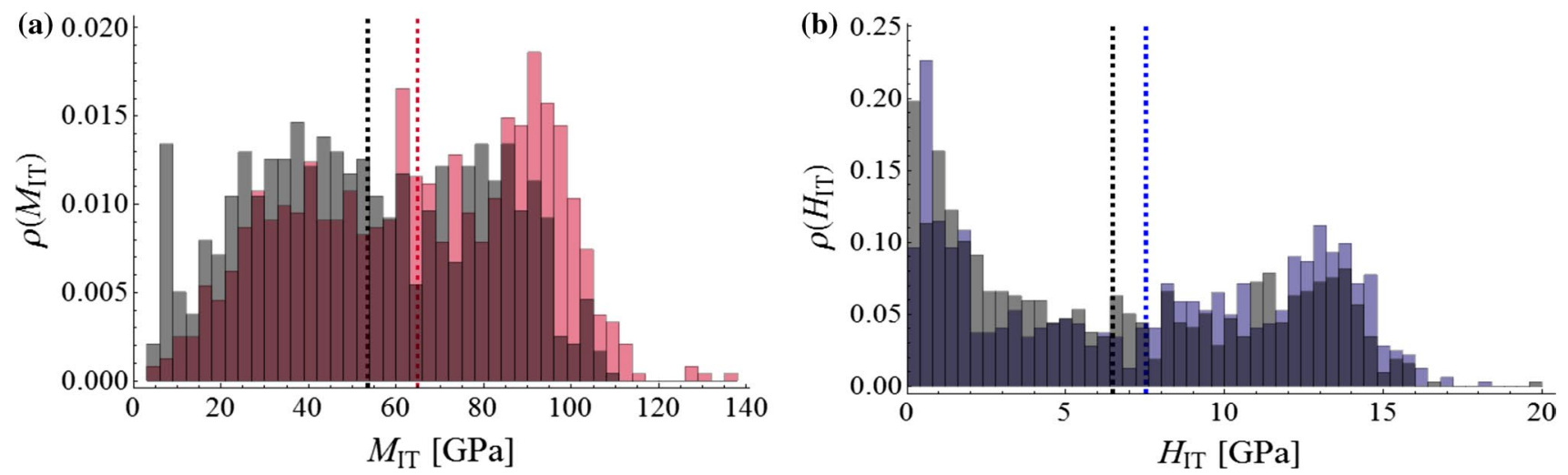

Fig. 29 The very fine-grained sandstone: a histogram of the indentation modulus; $\mathbf{b}$ histogram of hardness
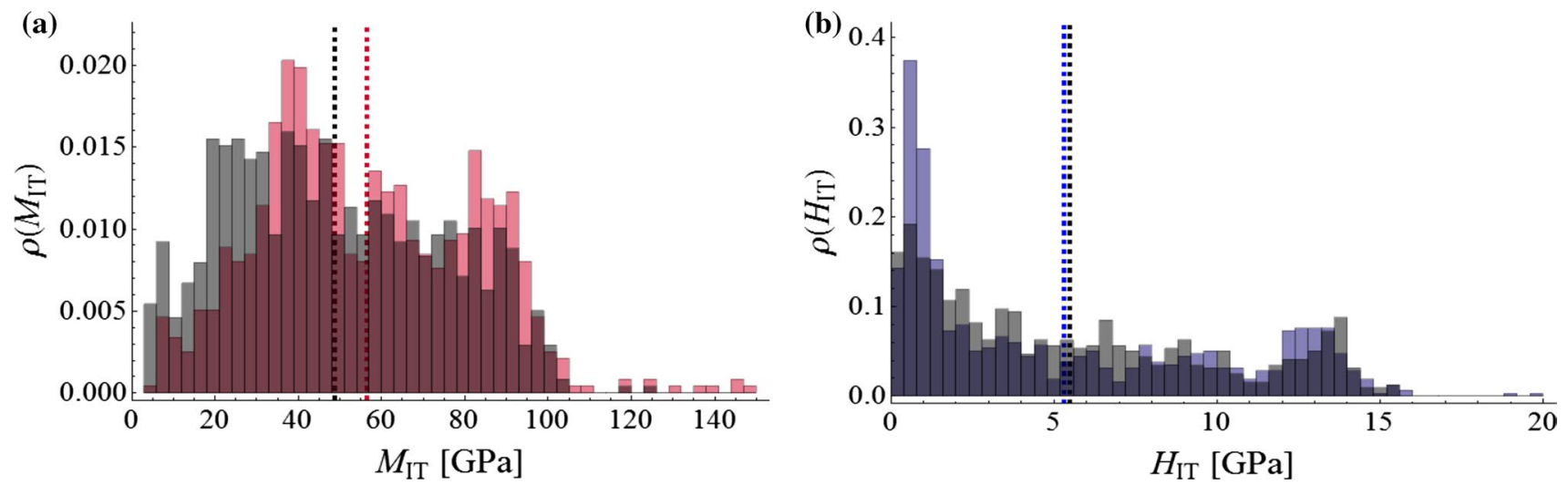

Fig. 30 The medium-grained sandstone: a histogram of the indentation modulus; $\mathbf{b}$ histogram of hardness

a sudden increase in the value of this coefficient. Then there is a decrease in its value up to the temperature of about $700{ }^{\circ} \mathrm{C}$. After exceeding the temperature $700^{\circ} \mathrm{C}$, $\mathrm{E} / \mathrm{UCS}$ is almost constant.
Unfortunately, taking into account a limited number of tests and high scatter of the results, the above stated observations can only be interpreted as qualitative information. Quantitative analyses require to be performed by the other, 
Table 3 Summary of the indentation results for tested sandstones

\begin{tabular}{llllll}
\hline Sandstone & $\begin{array}{l}\text { Tempera- } \\
\text { ture }\left({ }^{\circ} \mathrm{C}\right)\end{array}$ & $\begin{array}{l}\mu^{M_{\mathrm{IT}}} \\
{[\mathrm{GPa}]}\end{array}$ & $\begin{array}{l}\sigma^{M_{\mathrm{IT}}} \\
{[\mathrm{GPa}]}\end{array}$ & $\begin{array}{l}\mu^{H_{\mathrm{IT}}} \\
{[\mathrm{GPa}]}\end{array}$ & $\begin{array}{l}\sigma^{H_{\mathrm{IT}}} \\
{[\mathrm{GPa}]}\end{array}$ \\
\hline Very fine-grained & 23 & 64.88 & 26.98 & 7.54 & 5.13 \\
& 1000 & 53.48 & 26.42 & 6.46 & 4.90 \\
Medium-grained & 23 & 56.48 & 25.39 & 5.31 & 4.83 \\
& 1000 & 48.86 & 25.45 & 5.50 & 4.44 \\
\hline
\end{tabular}

more thorough testing technique, ensuring appropriate level of statistical significance. Theoretically, one could attempt to perform a very large number of meso-scale tests to increase the confidence level of mean values. However, on the other hand, the large number of specimens triggers that the assumption that we still test the same rock material is likely to be no longer valid. For this reason, we proposed to extend the testing procedure to include tests at the micro-scale.

In the case of nano-indentation tests the following observations can be stated. Generally, the qualitative trends observed at meso-scale have been confirmed. The mean value of the indentation modulus, being the measure of the elastic response of rock, after the exposure to the temperature of $1000{ }^{\circ} \mathrm{C}$, decreases for both sandstones (see also Figs. 29a and 30a and Table 3). Furthermore, the mean value of the indentation modulus after heating-cooling cycle amounts to $82 \%$ and $87 \%$ of the reference value of indentation modulus (determined at $23{ }^{\circ} \mathrm{C}$ prior to high-temperature treatment) for the very fine- and medium-grained sandstones, respectively. Therefore, the micro-scale analyses exhibit the decrease of the stiffness at the micro-scale which was also identified at meso-scale. In this sense, the micro-scale results relate well with the decrease of Young's modulus value at meso-scale.

The hardness, determined in the nanoindentation tests, behaves in a different manner depending on the grain size of the sandstone. For the very fine-grained sandstone, the mean value of hardness decreased as a result of exposure to the temperature $1000{ }^{\circ} \mathrm{C}$ - from 7.54 to $6.46 \mathrm{GPa}$ (see also Figs. 29b and 30b and Table 3). For the mediumgrained sandstone the mean value of hardness (calculated from all 800 individual results-with no segmentation applied) increased slightly under the effect of thermal treatment; hardness $H_{\mathrm{IT}}$ increased from 5.31 to $5.50 \mathrm{GPa}$. As mentioned, it is the hardness which is the property corresponding to the strength of microstructure. Therefore, in the case of medium-grained sandstone a slight strengthening

\section{Very fine-grained sandstone}
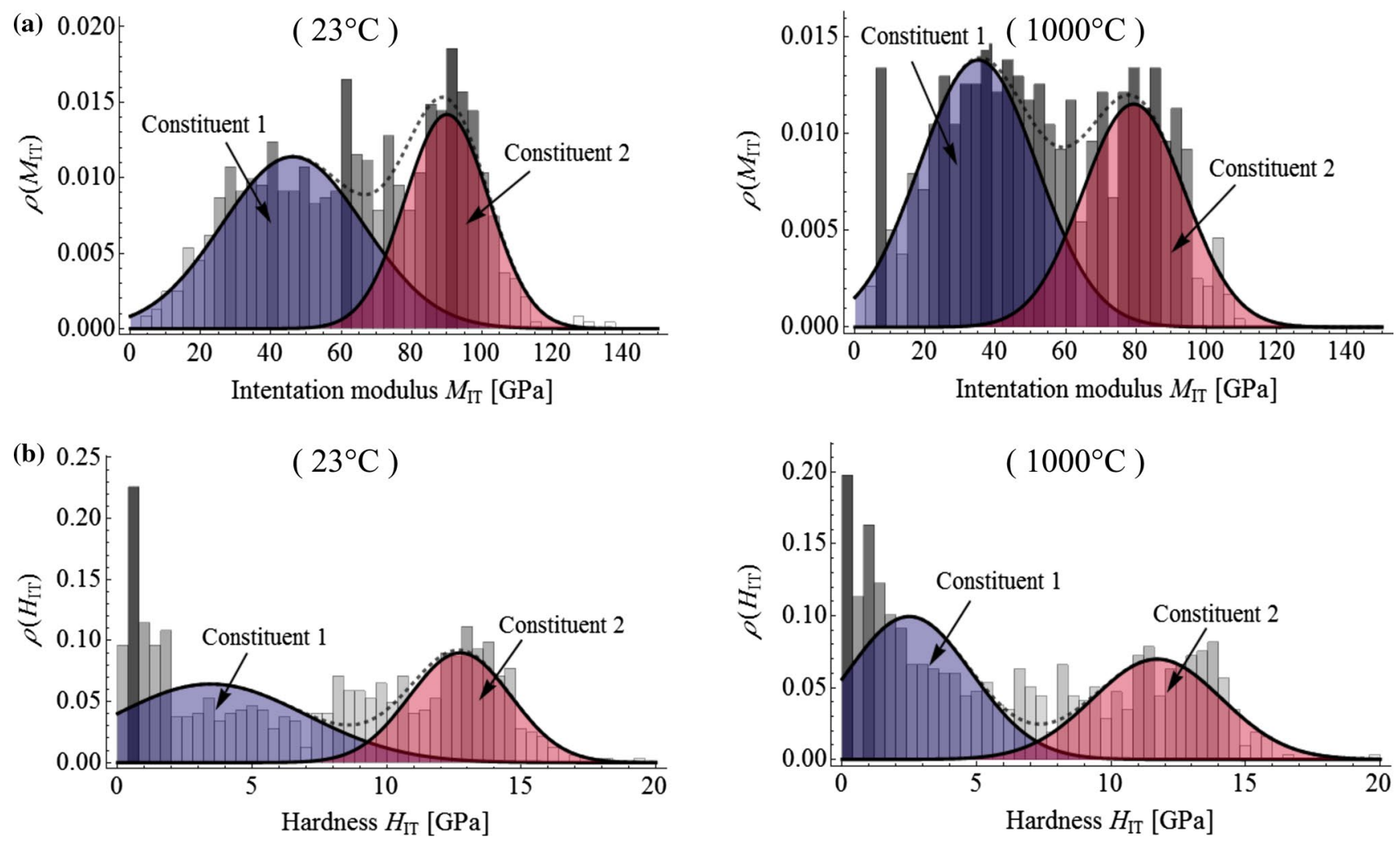

Fig. 31 Results of deconvolution for the very fine-grained sandstone: a indentation modulus; $\mathbf{b}$ hardness 


\section{Medium-grained sandstone}
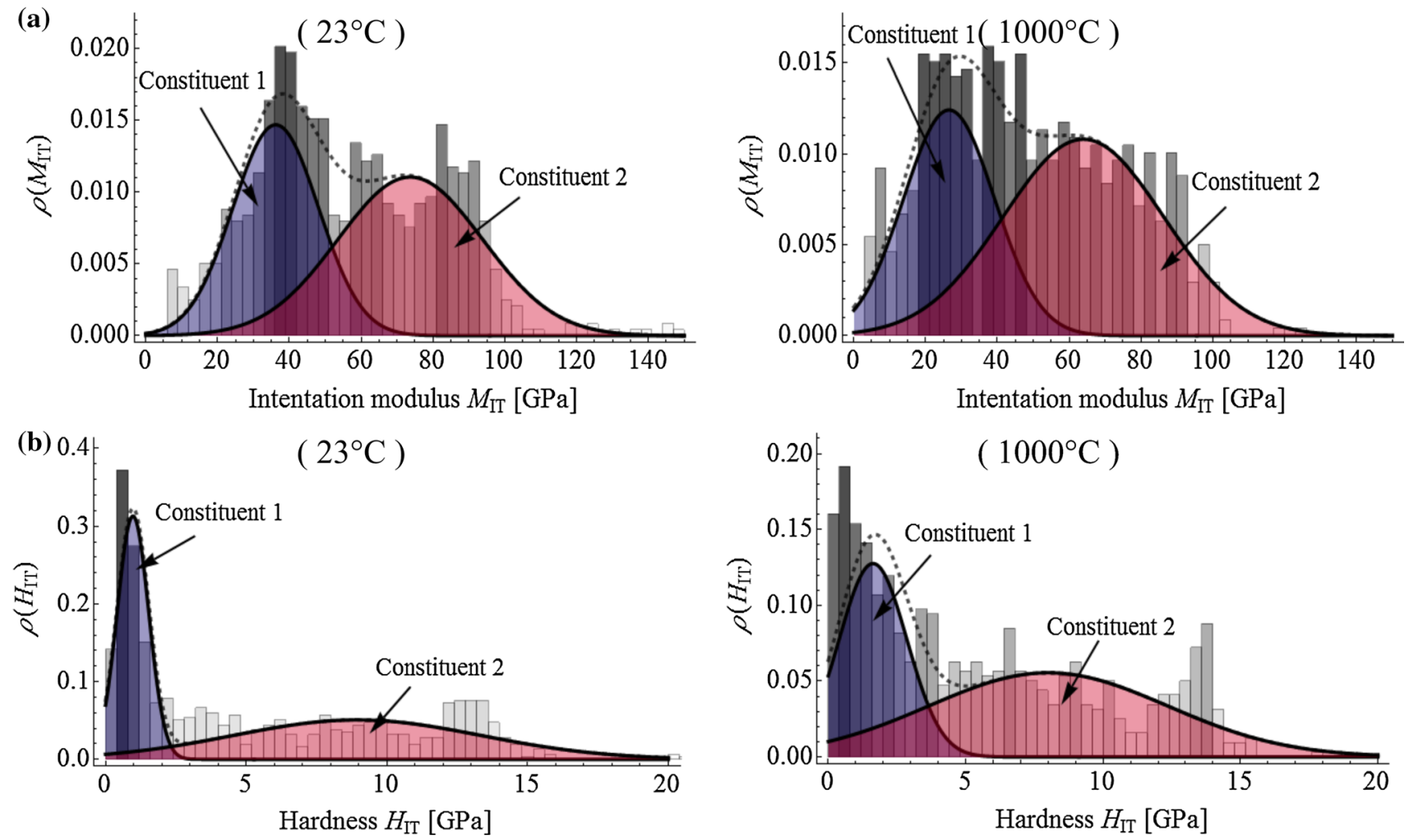

Fig. 32 Results of deconvolution for the medium-grained sandstone: $\mathbf{a}$ indentation modulus; $\mathbf{b}$ hardness

Table 4 The mean values of indentation modulus, hardness and volume fractions of individual components

\begin{tabular}{|c|c|c|c|c|c|c|c|}
\hline \multirow{3}{*}{$\begin{array}{l}\text { Sandstone } \\
\text { (no. of constituent) } j-\end{array}$} & \multirow{3}{*}{ Temperature } & \multirow{2}{*}{\multicolumn{2}{|c|}{$\frac{\mu_{j}^{M_{\mathrm{IT}}}}{[\mathrm{GPa}]}$}} & \multirow{2}{*}{\multicolumn{2}{|c|}{$\frac{\mu_{j}^{H_{\mathrm{IT}}}}{[\mathrm{GPa}]}$}} & \multirow{2}{*}{\multicolumn{2}{|c|}{$\frac{f_{j}}{[-]}$}} \\
\hline & & & & & & & \\
\hline & & 1 & 2 & 1 & 2 & 1 & 2 \\
\hline \multirow[t]{2}{*}{ very fine-grained } & $\left(23^{\circ} \mathrm{C}\right)$ & 46.21 & 90.06 & 3.46 & 12.73 & 0.58 & 0.42 \\
\hline & $\left(1000^{\circ} \mathrm{C}\right)$ & 35.09 & 79.34 & 2.49 & 11.71 & 0.58 & 0.42 \\
\hline \multirow{2}{*}{ medium-grained } & $\left(23^{\circ} \mathrm{C}\right)$ & 36.19 & 73.67 & 0.97 & 8.94 & 0.44 & 0.56 \\
\hline & $\left(1000{ }^{\circ} \mathrm{C}\right)$ & 26.53 & 63.94 & 1.63 & 8.00 & 0.40 & 0.60 \\
\hline
\end{tabular}

of the microstructure is identified by nanoindentation tests. Again, this effect is reflected at the meso-scale where a slight increase of uniaxial compressive strength (from $43.8 \mathrm{MPa}$ at $T=23{ }^{\circ} \mathrm{C}$ to $55.4 \mathrm{MPa}$ at $T=1000{ }^{\circ} \mathrm{C}$ ) is also observed.

As already mentioned, the advantage of nanoindentation (compared to meso-scale investigation) is the possibility to carry out a large number of tests on the same rock material and consequently-despite the heterogeneity of the material-to perform a quantitative analysis on the assumed level of statistical significance. According to works [43, 44], based on the Central Limit Theorem, it is possible to determine the minimum number of tests $n$ ensuring statistical representativity with assumed relative error and confidence level:

$n \geq\left(\frac{\Phi^{-1}(1-\alpha / 2) \cdot \sigma}{\mu \cdot \varepsilon_{\mathrm{rel}}}\right)^{2}$,

where $\mu$ and $\sigma$ are mean value and standard deviation of measured quantities (modulus of indentation or hardness), $\Phi$ is the standard normal cumulative distribution function, $\alpha$ is the significance level, and $\varepsilon_{\text {rel }}$ is the relative error of estimation (for example if $\alpha=5 \%$ then $\Phi^{-1}(0.975)=1.96$ ). In general, the standard deviation $\sigma$ as well as the mean value $\mu$ are not known a priori. Therefore, the required number of 
Table 5 Summary of the results obtained for two extreme cases of temperature treatment

\begin{tabular}{|c|c|c|c|c|c|c|}
\hline & & & \multicolumn{4}{|l|}{ Sandstone } \\
\hline & & & $\begin{array}{l}\text { Very fine- } \\
\text { grained } \\
\left(T=23{ }^{\circ} \mathrm{C}\right)\end{array}$ & $\begin{array}{l}\text { Very fine- } \\
\text { grained } \\
\left(T=1000{ }^{\circ} \mathrm{C}\right)\end{array}$ & $\begin{array}{l}\text { Medium- } \\
\text { grained } \\
\left(T=23^{\circ} \mathrm{C}\right)\end{array}$ & $\begin{array}{l}\text { Medium- } \\
\text { grained } \\
\left(T=1000{ }^{\circ} \mathrm{C}\right)\end{array}$ \\
\hline \multirow[t]{4}{*}{ Uniaxial compression tests } & $\begin{array}{l}\text { Mean value of uniaxial compressive } \\
\text { strength }\end{array}$ & {$[\mathrm{MPa}]$} & 49.0 & 23.2 & 43.8 & 55.4 \\
\hline & $\begin{array}{l}\text { St. deviation uniaxial compressive } \\
\text { strength }\end{array}$ & {$[\mathrm{MPa}]$} & 10.5 & 8.6 & 7.6 & 7.8 \\
\hline & Young's modulus & {$[\mathrm{GPa}]$} & 7.11 & 2.59 & 6.51 & 4.16 \\
\hline & St. deviation of Young's modulus & [GPa] & 2.44 & 0.76 & 2.14 & 2.46 \\
\hline \multirow[t]{4}{*}{ Nanoindentation tests } & Mean value of indentation modulus & [GPa] & 64.8 & 53.4 & 56.4 & 48.8 \\
\hline & St. deviation of indentation modulus & {$[\mathrm{GPa}]$} & 26.9 & 26.4 & 25.3 & 25.4 \\
\hline & Mean value of hardness & [GPa] & 7.54 & 6.46 & 5.31 & 5.50 \\
\hline & St. deviation of hardness & [GPa] & 5.13 & 4.90 & 4.83 & 4.44 \\
\hline \multirow[t]{5}{*}{ Micro-computed tomography } & Mean value of grey scale & [0-255] & 85.3 & 81.3 & 88.0 & 84.2 \\
\hline & St. deviation of grey level & {$[0-255]$} & 28.6 & 24.4 & 19.3 & 24.2 \\
\hline & Porosity & {$[-]$} & 5.74 & 7.91 & 0.33 & 4.83 \\
\hline & Specific surface & {$[1 / \mathrm{m}]$} & 22.2 & 32.0 & 4.54 & 25.1 \\
\hline & Mean local pore thickness & {$[\mu \mathrm{m}]$} & 12.7 & 11.4 & 7.29 & 7.89 \\
\hline
\end{tabular}

tests has to be determined by the implicit procedure. After completing a series of tests the standard deviation $\sigma$ and mean value $\mu$ are to be estimated. Then, the condition (3) is verified: if it is not met, another sequence of tests must be performed.

With regards to the presented results it can be stated that, apart from the hardness of medium-grained sandstone (which is characterized by very high variability), for all the other cases it holds true that the number of tests used, i.e., $n=800$ ensures statistical representativity of the mean value. The condition is satisfied for both, indentation modulus and hardness, at a confidence level $95 \%$ with the relative error not exceeding 5\%. Moreover, this is met for the results obtained for each of the considered cases of thermal treatment. Consequently, if the relative change in mechanical parameter, due to thermal treatment, is greater than $5 \%$ then the application of the proposed methodology to identify such modification is justified. Hence, even relatively small changes in the rock properties due to thermal modification can be quantitatively assessed by the proposed approach.

Another benefit of indentation testing at the micro-scale is the possibility of performing the procedure of deconvolution to assess not only mean values, but also to distinguish constituents of rock microstructure and to characterize them quantitatively in the statistical sense [40]. Within the present study - as a result of deconvolution - the original, complex mineral composition of both sandstones was virtually replaced by two components, understood as clusters of minerals. The component 1 is characterized by relatively low strength whereas the component 2 has the higher strength.
With this regard, the following observations can be stated (see Figs. 31-32 and Table 4):

1. The average value of the indentation modulus, for each of the sandstones' components, decreased due to high temperature treatment.

2. In the case of very fine-grained sandstone the strength of both components decreased due to the exposure to temperature of $1000^{\circ} \mathrm{C}$.

3. In the case of medium-grained sandstone the "weaker" constituent (component 1) was strengthened due to the exposure to high temperature-the hardness value increased from 0.97 to $1.63 \mathrm{GPa}$. This means that the strength of minerals forming component 1 increased. At the same time, the hardness of the component 2 decreased from 8.94 to $8.00 \mathrm{GPa}$. Therefore, the constituent 1 makes the main contribution to the increase in mean hardness (from 5.31 to $5.50 \mathrm{GPa}$ - see Table 3). This observation is in a good agreement with the increase in overall rock strength identified at the mesoscale tests (UCS).

What is commonly known, the overall properties (corresponding to those evaluated at the meso-scale) of microheterogeneous materials are not only affected by mechanical parameters of individual components but also by the microstructure morphology [45]. Therefore we decided to extend the methodology by imaging with the use of microcomputed tomography. The results enabled the assessment of the morphology changes in the microstructure of both 
sandstones due to high temperature treatment. In the preliminary research presented in this work microstructural changes are primarily determined by the formation of cracks on intergranular contacts. The conducted analyses allowed the evolution of the microstructure to be characterised in a quantitative way. The decrease in the average value of the grey scale indicates the reduction of bulk density due to the exposure to temperature treatment. This tendency was observed for both sandstones. It may be the result of both, changes in the chemical composition (annealing/burning of minerals) as well as the appearance of the microcracks on intergranular contacts. In both samples an increase in porosity after heating-cooling cycle was observed. This increase is by approximately $40 \%$ in the very fine-grained sandstone, whereas in the medium-grained sandstone the porosity increased much more evidently - the increase was by approximately 15 fold-from the initial value of $0.33 \%$ for $23{ }^{\circ} \mathrm{C}$ to $4.83 \%$ after exposure to the temperature of $1000{ }^{\circ} \mathrm{C}$. The changes in the average pore thickness are small, characterized only by slight differences, to the order of about $10 \%$. In the sample of very fine-grained sandstone the average local pore thickness decreased, whereas in the second tested sandstone value of this parameter increased. While the average pore thickness does not change significantly, the temperature effect is clearly reflected in the increase of the specific surface. This parameter grows by half in the very fine-grained sandstone, whereas in the medium-grained sandstone, characterized by very low initial porosity, the specific surface increased by more than 5 times.

The results of X-Ray micro-computed tomography in connection with subsequent morphometric analysis-as shown in the paper - can be used to verify changes in microstructure morphology that occur in the rock material due to thermal modification. Such investigations are of primary importance due to the fact that improving the parameters of the individual components does not necessarily mean the improvement of the overall parameters of the rock at mesoscale. Thus, X-Ray micro-computed tomography can serve, e.g., as a tool to assess the material's intrinsic destruction due to thermal expansion and intergranular cracks development. Therefore, in the context of the methodology being developed, the role of micro-computed tomography imaging has to be considered very important.

\section{Conclusions}

The analyses presented in this work constitute a preliminary part of research project focussing on thermal modification of physical and mechanical properties of mining waste rocks for the purpose of their possible application in geoengineering practice. Thus, the main goal of the presented study was to formulate the methodology combining micro- and meso-scale laboratory techniques to identify the changes in rock properties induced by high-temperature treatment. This methodology is going to be used in the future as a tool for controlling a process of thermal modification of mining waste. Properly modified waste rock material may be used in geotechnical practice, for instance, as road foundation, material for the construction of embankments or aggregate for concrete. In this context, the mechanical parameters at the meso-scale are of primary importance. Usually, these parameters are obtained from uniaxial compression tests. However, because of the heterogeneous nature of rock material and limitations in the number of specimens, entailing large deviation of the measurements, the thermal modification process cannot be relied solely on meso-scale investigation. Thus, a quantitative analysis has to be performed by another, more thorough testing technique, ensuring suitable statistical significance, i.e. assumed confidence level and acceptable relative error of the measurement. Such requirements are satisfied by the grid indentation technique applied at the micro-scale.

In the particular case, the nanoindentation tests results are in agreement with the qualitative trends observed at meso-scale for both sandstones under investigation. What is more important, we proposed the implicit procedure for determination of required number of tests ensuring statistical significance of calculated mean values. Furthermore, it has been shown that the "realistic" number of tests, equal to 800 , can be sufficient in a practical case (this however has to be treated as a value dependent on individual conditions, i.e., changing the rock material or the temperature will probably affect the required number of tests). Therefore, the proposed approach is justified in conducting quantitative analyses. Nevertheless, we have to take into account a fact that the overall properties (corresponding to those at the meso-scale) of micro-heterogeneous materials are not only affected by mechanical parameters of individual components but also by the microstructure morphology [45]. Therefore, we decided to extend the methodology by $3 \mathrm{D}$ imaging with the use of micro-computed tomography to assess the thermally induced changes in the morphology of rocks microstructure. Regarding the results obtained for both sandstones, these changes were determined by the formation of cracks on intergranular contacts. This specific result is due to the use of a high nominal temperature, $T=1000{ }^{\circ} \mathrm{C}$. Regardless of this particular observation, the following general conclusion is drawn: the combined use of nanoindentation and micro-computed tomography allows one to identify the changes occurring (at the microscale) in rock due to thermal treatment. In addition, based on the methods of micromechanics (computational or analytical ones), the changes at the meso-scale can also be assessed using information revealed by proposed technique. What is more-to put it simply-if the parameters 
of the components have improved and the microstructure has not deteriorated, then the overall parameters of the rock have improved. This corresponds to the "ideal" case we will be looking for in the future stages of the research project aiming at thermal modification of rock waste.

Another benefit of grid indentation testing at the microscale is the possibility of performing the procedure of deconvolution to assess not only mean values, but also to distinguish constituents of rock microstructure and to characterize them quantitatively in the statistical sense [40]. This would state very interesting topic of deeper insight into thermally induced changes in rocks at the micro-scale level, especially in combination with simultaneous recognition of the mineral composition. Then, the deconvolution procedure, based on the nanoindentation results, should incorporate the original multi-component nature of rock microstructure-this will be the subject of future works. Nevertheless, the proposed methodology combining use of investigation techniques at meso- and micro-scale proved to be a useful tool for the assessment of the effects of hightemperature treatment in the changes of rock properties.

Funding A part of investigations, namely the meso-scale research, was conducted in Central Mining Institute under Research Project No. 11163028 funded by the Ministry of Science and Higher Education (Poland), titled Thermal modification of properties of carboniferous clastic rocks from mining waste in the aspect of improving their quality for practical applications in geoengineering.

Code availability Software application and custom code.

\section{Compliance with ethical standards}

Conflict of interest The authors declare that they have no conflict of interest.

Open Access This article is licensed under a Creative Commons Attribution 4.0 International License, which permits use, sharing, adaptation, distribution and reproduction in any medium or format, as long as you give appropriate credit to the original author(s) and the source, provide a link to the Creative Commons licence, and indicate if changes were made. The images or other third party material in this article are included in the article's Creative Commons licence, unless indicated otherwise in a credit line to the material. If material is not included in the article's Creative Commons licence and your intended use is not permitted by statutory regulation or exceeds the permitted use, you will need to obtain permission directly from the copyright holder. To view a copy of this licence, visit http://creativecommons.org/licenses/by/4.0/.

\section{References}

1. Ferrero AM, Marini P. Experimental studies on the mechanical behaviour of two thermal cracked marbles. Rock Mech Rock Eng. 2001;34:57-66. https://doi.org/10.1007/s006030170026.
2. Hajpál M, Török Á. Mineralogical and colour changes of quartz sandstones by heat. Env Geol. 2004;46:311-22. https://doi. org/10.1007/s00254-004-1034-z.

3. Liang WG, Xu SG, Zhao YS. Experimental study of temperature effects on physical and mechanical characteristics of salt rock. Rock Mech Rock Eng. 2006;39:469-82. https://doi.org/10.1007/ s00603-005-0067-2.

4. Liu X, Yuan S, Sieffert Y, Fityus S, Buzzi O. Changes in mineralogy, microstructure, compressive strength and intrinsic permeability of two sedimentary rocks subjected to high-temperature heating. Rock Mech Rock Eng. 2016;49:2985-98. https://doi. org/10.1007/s00603-016-0950-z.

5. Yavuz H, Demirdag S, Caran S. Thermal effect on the physical properties of carbonate rocks. Int J Rock Mech Min Sci. 2010;47:94-103. https://doi.org/10.1016/j.ijrmms.2009.09.014.

6. Younger PL. Hydrogeological and geomechanical aspects of underground coal gasification and its direct coupling to carbon capture and storage. Mine Water Environ. 2011;30:127-40. https ://doi.org/10.1007/s10230-011-0145-5.

7. Tsang C-F. Linking thermal, hydrological, and mechanical processes in fractured rocks. Annu Rev Earth Planet Sci. 1999;27:359-84. https://doi.org/10.1146/annurev.earth.27.1.359.

8. Adam D, Markiewicz R. Energy from earth-coupled structures, foundations, tunnels and sewers. Géotechnique. 2009;59:229-36. https://doi.org/10.1680/geot.2009.59.3.229.

9. Dean SW, Takarli M, Prince-Agbodjan W. Temperature effects on physical properties and mechanical behavior of granite: experimental investigation of material damage. J ASTM Int. 2008;5:100464. https://doi.org/10.1520/JAI100464.

10. R. P. g., D.R. Viete, B.J. Chen, M.S.A. Perera, Transformation plasticity and the effect of temperature on the mechanical behaviour of Hawkesbury sandstone at atmospheric pressure, Engineering Geology. 151 (2012) 120-127. https://doi.org/10.1016/j.engge o.2012.09.007.

11. Sygała A, Bukowska M, Janoszek T. High temperature versus geomechanical parameters of selected rocks - the present state of research. J Sustain Min. 2013;12:45-51. https://doi.org/10.7424/ jsm130407.

12. Tian H, Kempka T, Yu S, Ziegler M. Mechanical properties of sandstones exposed to high temperature. Rock Mech Rock Eng. 2016;49:321-7. https://doi.org/10.1007/s00603-015-0724-z.

13. Mahanta B, Singh TN, Ranjith PG. Influence of thermal treatment on mode I fracture toughness of certain Indian rocks. Eng Geol. 2016;210:103-14. https://doi.org/10.1016/j.enggeo.2016.06.008.

14. Cao P, Liu T, Pu C, Lin H. Crack propagation and coalescence of brittle rock-like specimens with pre-existing cracks in compression. Eng Geol. 2015;187:113-21. https://doi.org/10.1016/j.engge o.2014.12.010.

15. Sirdesai NN, Mahanta B, Ranjith PG, Singh TN. Effects of thermal treatment on physico-morphological properties of Indian finegrained sandstone. Bull Eng Geol Environ. 2019;78:883-97. https ://doi.org/10.1007/s10064-017-1149-6.

16. Chen Y-L, Wang S-R, Ni J, Azzam R, Fernández-steeger TM. An experimental study of the mechanical properties of granite after high temperature exposure based on mineral characteristics. Eng Geol. 2017;220:234-42. https://doi.org/10.1016/j.engge o.2017.02.010.

17. Siegesmund S, Mosch S, Scheffzük Ch, Nikolayev DI. The bowing potential of granitic rocks: rock fabrics, thermal properties and residual strain. Environ Geol. 2008;55:1437-48. https://doi. org/10.1007/s00254-007-1094-y.

18. Somerton WH, Thermal properties and temperature-related behavior of rock/fluid systems, Elsevier, 1992.

19. Pinińska J, The influence of elevated temperature on the mechanical properties of rocks. Works of the Institute of Geotechnics and 
Hydrotechnics of the Wrocław University of Technology, in: 2007: pp. 527-534.

20. Keshavarz M, Pellet FL, Loret B. Damage and changes in mechanical properties of a gabbro thermally loaded up to $1,000^{\circ} \mathrm{C}$. Pure Appl Geophys. 2010;167:1511-23. https://doi.org/10.1007/s0002 4-010-0130-0.

21. Dimitriyev AP, Kusyayev LS, Protasov YI, Yamschichikov VS. Physical properties of rocks at high temperature (translated from Russian). Moskva: Nedra; 1969.

22. Rao Q, Wang Z, Xie H, Xie Q. Experimental study of mechanical properties of sandstone at high temperature. J Cent South Univ Technol. 2007;14:478-83. https://doi.org/10.1007/s1177 1-007-0311-x.

23. Chen Y-L, Ni J, Shao W, Azzam R. Experimental study on the influence of temperature on the mechanical properties of granite under uni-axial compression and fatigue loading. Int J Rock Mech Min Sci. 2012;56:62-6. https://doi.org/10.1016/j.ijrmm s.2012.07.026.

24. Lintao Y, Marshall AM, Wanatowski D, Stace R, Ekneligoda T. Effect of high temperatures on sandstone - a computed tomography scan study. Int J Phys Model Geotech. 2017;17:75-90. https ://doi.org/10.1680/jphmg.15.00031.

25. Fan Z, Wei H, Han-qun G, Da-wei H, Qian S, Jian-fu S, Nanoindentation tests on granite after heat treatment, Rock and Soil Mechanics. 39 (2018) 235-+.

26. Stefaniuk D, Tankiewicz M, Stróżyk J. X-Ray microtomography $(\mu \mathrm{CT})$ as a useful tool for visualization and interpretation of shear strength test results. Studia Geotechnica et Mechanica. 2015;36:47-55. https://doi.org/10.2478/sgem-2014-0035.

27. Cała M, Cyran K, Kawa M, Kolano M, Łydżba D, Pachnicz M, Rajczakowska M, Różański A, Sobótka M, Stefaniuk D, Stopkowicz A, Wałach D. Identification of microstructural properties of shale by combined use of X-ray micro-CT and nanoindentation tests. Procedia Eng. 2017;191:735-43. https://doi.org/10.1016/j. proeng.2017.05.239

28. Bukowska M. Inclination of the rock mass to rockburst-geological and geomechanical test methods. Katowice: Central Mining Institute; 2012

29. Brown ET, The ISRM Suggested Methods for Rock Characterization, Testing and Monitoring: 2007-2014, R. Ulusay (Ed.), Springer International Publishing, Cham, Switzerland (2015), p. 293,(83.29€. ISBN 978-3-319-07712-3 (Hbk), 978-3-31907713-0 (eBook)), Elsevier, 2015.

30. Landis EN, Keane DT. X-ray microtomography. Mater Charact. 2010;61:1305-16. https://doi.org/10.1016/j.matchar.2010.09.012.

31. Feldkamp LA, Davis LC, Kress JW. Practical cone-beam algorithm. J Opt Soc Am A. 1984;1:612. https://doi.org/10.1364/ JOSAA.1.000612.

32. Rodet T, Noo F, Defrise M. The cone-beam algorithm of Feldkamp, Davis, and Kress preserves oblique line integrals. Med Phys. 2004;31:1972-5. https://doi.org/10.1118/1.1759828.

33. Oliver WC, Pharr GM. An improved technique for determining hardness and elastic modulus using load and displacement sensing indentation experiments. J Mater Res. 1992;7:1564-83. https:// doi.org/10.1557/JMR.1992.1564.
34. Oliver WC, Pharr GM. Measurement of hardness and elastic modulus by instrumented indentation: advances in understanding and refinements to methodology. J Mater Res. 2004;19:3-20. https:// doi.org/10.1557/jmr.2004.19.1.3.

35. Sneddon IN. The relation between load and penetration in the axisymmetric boussinesq problem for a punch of arbitrary profile. Int J Eng Sci. 1965;3:47-57. https://doi.org/10.1016/00207225(65)90019-4.

36. Bolshakov A, Pharr GM. Inaccuracies in Sneddon's solution for elastic indentation by a rigid cone and their implications for nanoindentation data analysis. MRS Proc. 1996;436:189. https:// doi.org/10.1557/PROC-436-189.

37. Constantinides G, Ulm F-J, Van Vliet K. On the use of nanoindentation for cementitious materials. Mat Struct. 2003;36:191-6. https://doi.org/10.1007/BF02479557.

38. Hildebrand T, Rüegsegger P. A new method for the modelindependent assessment of thickness in three-dimensional images. J Microsc. 1997;185:67-75. https://doi.org/10.104 6/j.1365-2818.1997.1340694.x.

39. Michałek J, Pachnicz M, Sobótka M. Application of nanoindentation and 2D and 3D imaging to characterise selected features of the internal microstructure of spun concrete. Materials. 2019;12:1016. https://doi.org/10.3390/ma12071016.

40. Bobko C, Ulm F-J. The nano-mechanical morphology of shale. Mech Mater. 2008;40:318-37. https://doi.org/10.1016/j.mechm at.2007.09.006

41. Cariou S, Ulm F-J, Dormieux L. Hardness-packing density scaling relations for cohesive-frictional porous materials. J Mech Phys Solids. 2008;56:924-52. https://doi.org/10.1016/j. jmps.2007.06.011.

42. Ganneau FP, Constantinides G, Ulm F-J. Dual-indentation technique for the assessment of strength properties of cohesive-frictional materials. Int J Solids Struct. 2006;43:1727-45. https://doi. org/10.1016/j.ijsolstr.2005.03.035.

43. Kanit T, Forest S, Galliet I, Mounoury V, Jeulin D. Determination of the size of the representative volume element for random composites: statistical and numerical approach. Int J Solids Struct. 2003;40:3647-79. https://doi.org/10.1016/S0020-7683(03)00143 $-4$.

44. Łydżba D, Różański A. Microstructure measures and the minimum size of a representative volume element: 2D numerical study. Acta Geophys. 2014;62:1060-86. https://doi.org/10.2478/ s11600-014-0226-5.

45. Torquato S, Random heterogeneous materials: microstructure and macroscopic properties, Springer Science \& Business Media, 2013.

Publisher's Note Springer Nature remains neutral with regard to jurisdictional claims in published maps and institutional affiliations. 